\title{
Simple Closed Analytic Formulas to approximate the First Two Legendre's Complete Elliptic Integrals by a Fast Converging Recurrent-Iterative Scheme
}

\author{
RICHARD SELESCU
}

Flow Physics Department, Experimental Aerodynamics Compartment, Trisonic Wind Tunnel Laboratory "Elie Carafoli" National Institute for Aerospace Research - INCAS (under the Aegis of the Romanian Academy) Bucharest, Sector 6, Bd. Iuliu Maniu, No. 220, Code 061126

ROMANIA

web page: http://www.incas.ro

Abstract: Two sets of closed analytic functions are proposed for the approximate calculus of the complete elliptic integrals $\mathrm{K}(k)$ and $\mathrm{E}(k)$ in the normal form due to Legendre, their expressions having a remarkable simplicity and accuracy. The special usefulness of the newly proposed formulas consists in they allow performing the analytic study of variation of the functions in which they appear, using derivatives (they being expressed in terms of elementary functions only, without any special function; this would mean replacing one difficulty by another of the same kind). Comparative tables of so found approximate values with the exact ones, reproduced from special functions tables, are given (vs. the elliptic integrals' modulus $k$ ). The $1^{\text {st }}$ set of formulas was suggested by Peano's law on ellipse's perimeter. The new functions and their derivatives coincide with the exact ones at the left domain's end only. As for their simplicity, the formulas in $k / k^{\prime}$ do not need mathematical tables (are purely algebraic). As for accuracy, the $2^{\text {nd }}$ set, more intricate, gives more accurate values and extends itself more closely to the right domain's end. An original fast converging recurrent-iterative scheme to get sets of formulas with the desired accuracy is given in appendix.

Key-Words: analytic methods; Legendre complete elliptic integrals $\mathrm{K}(k)$ and $\mathrm{E}(k)$; elliptic integrals' moduli $k$ and complementary $k^{\prime}$; tables of Legendre complete elliptic integrals; recurrent-iterative scheme; Peano's approximate law for the ellipse perimeter

Received: January 7, 2021. Revised: May 21, 2021. Accepted: June 14, 2021. Published: July 6, 2021.

\section{Introduction - elliptic integrals}

There are many interesting domains in pure and applied mathematics where appear both (or, often, only one) complete elliptic integrals of the $1^{\text {st }}$ and $2^{\text {nd }}$ kind in the normal form due to Legendre. The arc length of a lemniscate, as well as the period of oscillations in a vacuum of the simple pendulum, in the dynamics of a constrained heavy particle, are given by a complete elliptic integral of the $1^{\mathrm{t}} \mathrm{kind}$. The perimeter of an ellipse, as well as the lift coefficient of a thin delta wing with subsonic leading edges, in supersonic aerodynamics (small perturbations theory), are given by a complete elliptic integral of the $2^{\text {nd }}$ kind. In electromagnetic theory, the electric and magnetic fields from a circular coil can be expressed using the complete elliptic integrals. The relations below define the integrals of the $1^{\text {st }}$ and $2^{\text {nd }}$ kind, in canonical form, $\mathrm{K}(k)$ and $\mathrm{E}(k)$, resp.: $\mathrm{K}(k)=\int_{0}^{\pi / 2}\left(1-k^{2} \sin ^{2} \varphi\right)^{-1 / 2} d \varphi=\int_{0}^{1}\left[\left(1-t^{2}\right)\left(1-k^{2} t^{2}\right)\right]^{-1 / 2} d t ;$ $\mathrm{E}(k)=\int_{0}^{\pi / 2}\left(1-k^{2} \sin ^{2} \varphi\right)^{1 / 2} d \varphi=\int_{0}^{1}\left[\left(1-t^{2}\right)\left(1-k^{2} t^{2}\right)\right]^{1 / 2} d t ;$ $k=\sin \theta \geq 0$ is called modulus. $\mathrm{K}(k), \mathrm{E}(k)$ are typical elliptic integrals. They do not admit primitive functions (cannot be expressed in terms of elementary functions), being calculated by expanding the integrands into series, integrating term-by-term, and presented vs. $k \in[0,1]$, or vs. $\theta \in[0, \pi / 2]$, in some mathematical tables [1]-[6]. Modern mathematics defines an elliptic integral as any function $f$ which can be expressed in the form $f(x)=\int_{c}^{x} R\left[t, P(t)^{1 / 2}\right] d t$; $R$ is a rational function of its two arguments; $P$ is a polynomial of degree 3 or 4 with no repeated roots; $c$ is a constant. The values given in some special tables allow performing the calculus for a given case (point), but not the analytic study of variation of the functions in which these integrals appear, using the derivatives. In chapter 2 two original sets (subscripts $0 ; 1$ ) of closed analytic functions are given for the approximate calculus of $\mathrm{K}(k)$ and $\mathrm{E}(k)$. We use an original purely analytic method (not some numerical, or sophisticated computer programs, like most authors). There also is a Legendre complete elliptic integral of the $3^{\text {trd }}$ kind. With an appropriate reduction formula, every elliptic integral can be brought into a form that involves integrals over rational functions and the three Legendre canonical forms (of the $1^{\text {st }}, 2^{\text {nd }} \& 3^{\text {rd }}$ kind).

\section{The two sets of newly proposed formulas}

The complementary modulus is $k^{\prime}=\left(1-k^{2}\right)^{1 / 2}=\cos \theta$. The $\mathrm{E}_{0}(k)$ formula in the $1^{\text {st }}$ set $\left(\mathrm{K}_{0}, \mathrm{E}_{0}\right)$ is suggested by Peano's law.

$$
\begin{aligned}
& \mathrm{K}_{0}(k)=\frac{\pi}{\sqrt[4]{1-k^{2}}}\left(1-\frac{1}{2 \sqrt{2}} \sqrt{\frac{1+\sqrt{1-k^{2}}}{\sqrt[4]{1-k^{2}}}}\right)=\pi\left(\frac{1}{\sqrt{k^{\prime}}}-\frac{1}{2 \sqrt{2}} \frac{\sqrt{1+k^{\prime}}}{k^{\prime 3 / 4}}\right), \\
& \mathrm{K}_{0}(\theta)=\frac{\pi}{\cos ^{1 / 2} \theta}\left(1-\frac{1}{2} \frac{\cos (\theta / 2)}{\cos ^{1 / 4} \theta}\right)=\pi\left(\frac{1}{\cos ^{1 / 2} \theta}-\frac{1}{2} \frac{\cos (\theta / 2)}{\cos ^{3 / 4} \theta}\right) . \\
& \mathrm{E}_{0}(k)=\frac{\pi}{4} \sqrt[4]{1-k^{2}}\left(\frac{3}{2} \frac{1+\sqrt{1-k^{2}}}{\sqrt[4]{1-k^{2}}}-1\right)=\frac{\pi}{4}\left(\frac{3}{2}\left(1+k^{\prime}\right)-\sqrt{k^{\prime}}\right], \\
& \mathrm{E}_{0}(\theta)=\frac{\pi}{4} \cos ^{1 / 2} \theta\left(3 \frac{\cos ^{2}(\theta / 2)}{\cos ^{1 / 2} \theta}-1\right)=\frac{\pi}{4}\left(3 \cos ^{2} \frac{\theta}{2}-\sqrt{\cos \theta}\right) .
\end{aligned}
$$

Similarly, for the $2^{\text {nd }} \operatorname{set}\left(\mathrm{K}_{1}, \mathrm{E}_{1}\right)$, are proposed the formulas: 


$$
\begin{aligned}
& \mathrm{K}_{1}(k)=\frac{\pi \sqrt{2}}{\sqrt{\left(1+k^{\prime}\right) \sqrt{k^{\prime}}}}\left(1-\frac{\sqrt[4]{2}}{4} \frac{1+\sqrt{k^{\prime}}}{\sqrt[4]{\left(1+k^{\prime}\right) \sqrt{k^{\prime}}}}\right), \\
& \mathrm{K}_{1}(\theta)=\frac{\pi}{\cos (\theta / 2) \cos ^{1 / 4} \theta}\left(1-\frac{1}{4} \frac{1+\cos ^{1 / 2} \theta}{\cos ^{1 / 2}(\theta / 2) \cos ^{1 / 8} \theta}\right) . \\
& \mathrm{E}_{1}(k)=\frac{\pi}{4}\left[\frac{3}{2}\left(1+\sqrt{k^{\prime}}\right)^{2}-\sqrt{2} \sqrt{1+k^{\prime}} \sqrt[4]{k^{\prime}}\right]-k^{\prime} \cdot \mathrm{K}_{1}(k), \\
& \mathrm{E}_{1}(\theta)=\frac{\pi}{4}\left[\frac{3}{2}(1+\sqrt{\cos \theta})^{2}-2 \cos \frac{\theta}{2} \sqrt[4]{\cos \theta}\right]-\cos \theta \cdot \mathrm{K}_{1}(\theta) .
\end{aligned}
$$

A $3^{\text {rd }}$ set $\left(K_{2}, E_{2}\right)$, even more accurate than previous two sets, can be built (a recurrent-iterative scheme) - see appendix.

Table 1. Values of the functions $\mathrm{K}$ (part one)

$\begin{array}{ccccc}\theta\left(^{\circ}\right) & k=\sin \theta & \mathrm{K}(k) & \mathrm{K}_{0}(k) & \mathrm{K}_{1}(k) \\ 0 & 0.00000 & 1.5708 & 1.5708 & 1.5708 \\ 1 & 0.01745 & 1.5709 & 1.5709 & 1.5709 \\ 2 & 0.03490 & 1.5713 & 1.5713 & 1.5713 \\ 3 & 0.05234 & 1.5719 & 1.5719 & 1.5719 \\ 4 & 0.06976 & 1.5727 & 1.5727 & 1.5727 \\ 5 & 0.08716 & 1.5738 & 1.5738 & 1.5738 \\ 6 & 0.10453 & 1.5751 & 1.5751 & 1.5751 \\ 7 & 0.12187 & 1.5767 & 1.5767 & 1.5767 \\ 8 & 0.13917 & 1.5785 & 1.5785 & 1.5785 \\ 9 & 0.15643 & 1.5805 & 1.5805 & 1.5805 \\ 10 & 0.17365 & 1.5828 & 1.5828 & 1.5828 \\ 11 & 0.19081 & 1.5854 & 1.5854 & 1.5854 \\ 12 & 0.20791 & 1.5882 & 1.5882 & 1.5882 \\ 13 & 0.22495 & 1.5913 & 1.5913 & 1.5913 \\ 14 & 0.24192 & 1.5946 & 1.5946 & 1.5946 \\ 15 & 0.25882 & 1.5981 & 1.5981 & 1.5981 \\ 16 & 0.27564 & 1.6020 & 1.6020 & 1.6020 \\ 17 & 0.29237 & 1.6061 & 1.6061 & 1.6061 \\ 18 & 0.30902 & 1.6105 & 1.6105 & 1.6105 \\ 19 & 0.32557 & 1.6151 & 1.6151 & 1.6151 \\ 20 & 0.34202 & 1.6200 & 1.6200 & 1.6200 \\ 21 & 0.35837 & 1.6252 & 1.6252 & 1.6252 \\ 22 & 0.37461 & 1.6307 & 1.6307 & 1.6307 \\ 23 & 0.39073 & 1.6365 & 1.6365 & 1.6365 \\ 24 & 0.40674 & 1.6426 & 1.6426 & 1.6426 \\ 25 & 0.42262 & 1.6490 & 1.6490 & 1.6490 \\ 26 & 0.43837 & 1.6557 & 1.6557 & 1.6557 \\ 27 & 0.45399 & 1.6627 & 1.6627 & 1.6627 \\ 28 & 0.46947 & 1.6701 & 1.6701 & 1.6701 \\ 29 & 0.48481 & 1.6777 & 1.6777 & 1.6777 \\ 30 & 0.50000 & 1.6858 & 1.6857 & 1.6858 \\ 31 & 0.51504 & 1.6941 & 1.6941 & 1.6941 \\ 32 & 0.52992 & 1.7028 & 1.7028 & 1.7028 \\ 33 & 0.54464 & 1.7119 & 1.7119 & 1.7119 \\ 34 & 0.55919 & 1.7214 & 1.7214 & 1.7214 \\ 35 & 0.57358 & 1.7312 & 1.7312 & 1.7312 \\ 36 & 0.58779 & 1.7415 & 1.7415 & 1.7415 \\ 37 & 0.60182 & 1.7522 & 1.7522 & 1.7522 \\ 38 & 0.61566 & 1.7633 & 1.7632 & 1.7633 \\ 39 & 0.62932 & 1.7748 & 1.7748 & 1.7748 \\ 40 & 0.64279 & 1.7868 & 1.7867 & 1.7868\end{array}$

$\begin{array}{ccccc}41 & 0.65606 & 1.7992 & 1.7992 & 1.7992 \\ 42 & 0.66913 & 1.8122 & 1.8121 & 1.8122 \\ 43 & 0.68200 & 1.8256 & 1.8256 & 1.8256 \\ 44 & 0.69466 & 1.8396 & 1.8395 & 1.8396 \\ 45 & 0.70711 & 1.8541 & 1.8540 & 1.8541 \\ 46 & 0.71934 & 1.8691 & 1.8691 & 1.8691 \\ 47 & 0.73135 & 1.8848 & 1.8847 & 1.8848 \\ 48 & 0.74314 & 1.9011 & 1.9009 & 1.9011 \\ 49 & 0.75471 & 1.9180 & 1.9178 & 1.9180 \\ 50 & 0.76604 & 1.9356 & 1.9354 & 1.9356 \\ 51 & 0.77715 & 1.9539 & 1.9536 & 1.9539 \\ 52 & 0.78801 & 1.9729 & 1.9726 & 1.9729 \\ 53 & 0.79864 & 1.9927 & 1.9923 & 1.9927 \\ 54 & 0.80902 & 2.0133 & 2.0128 & 2.0133 \\ 55 & 0.81915 & 2.0347 & 2.0341 & 2.0347 \\ 56 & 0.82904 & 2.0571 & 2.0564 & 2.0571 \\ 57 & 0.83867 & 2.0804 & 2.0795 & 2.0804 \\ 58 & 0.84805 & 2.1047 & 2.1037 & 2.1047 \\ 59 & 0.85717 & 2.1300 & 2.1288 & 2.1300 \\ 60 & 0.86603 & 2.1565 & 2.1551 & 2.1565 \\ 61 & 0.87462 & 2.1842 & 2.1825 & 2.1842 \\ 62 & 0.88295 & 2.2132 & 2.2111 & 2.2132 \\ 63 & 0.89101 & 2.2435 & 2.2410 & 2.2435 \\ 64 & 0.89879 & 2.2754 & 2.2723 & 2.2754 \\ 65 & 0.90631 & 2.3088 & 2.3051 & 2.3088 \\ 66 & 0.91355 & 2.3439 & 2.3394 & 2.3439 \\ 67 & 0.92050 & 2.3809 & 2.3754 & 2.3809 \\ 68 & 0.92718 & 2.4198 & 2.4132 & 2.4198 \\ 69 & 0.93358 & 2.4610 & 2.4530 & 2.4610 \\ 70 & 0.93969 & 2.5046 & 2.4948 & 2.5045 \\ 70.5 & 0.94264 & 2.5273 & 2.5165 & 2.5273 \\ 71 & 0.94552 & 2.5507 & 2.5389 & 2.5507 \\ 71.5 & 0.94832 & 2.5749 & & 2.5749 \\ 72 & 0.95106 & 2.5998 & & 2.5998 \\ 72.5 & 0.95372 & 2.6256 & & 2.6255 \\ 73 & 0.95630 & 2.6521 & & 2.6521 \\ 73.5 & 0.95882 & 2.6796 & & 2.6796 \\ 74 & 0.96126 & 2.7081 & & 2.7081 \\ 74.5 & 0.96363 & 2.7375 & & 2.7375 \\ 75 & 0.96593 & 2.7681 & & 2.7680 \\ 75.5 & 0.96815 & 2.7998 & & 2.7997 \\ 76 & 0.97030 & 2.8327 & & 2.8326 \\ 76.5 & 0.97237 & 2.8669 & & 2.8669 \\ 77 & 0.97437 & 2.9026 & & 2.9025 \\ 77.5 & 0.97630 & 2.9397 & & 2.9397 \\ 78 & 0.97815 & 2.9786 & & 2.9785 \\ 78.5 & 0.97992 & 3.0192 & & 3.0191 \\ 79 & 0.98163 & 3.0617 & & 3.0616 \\ 79.5 & 0.98325 & 3.1064 & & 3.1063 \\ 80 & 0.98481 & 3.1534 & & 3.1533 \\ 80.2 & 0.98541 & 3.1729 & & 3.1727 \\ 80.4 & 0.98600 & 3.1928 & & 3.1927 \\ 80.6 & 0.98657 & 3.2132 & & 3.2130 \\ 80.8 & 0.98714 & 3.2340 & & 3.2338 \\ 81 & 0.98769 & 3.2553 & & 3.2551\end{array}$


Table 1. Values of the functions K (part two)

\begin{tabular}{|c|c|c|c|c|}
\hline 81.2 & 0.98823 & 3.2771 & & 3.2769 \\
\hline 81.4 & 0.98876 & 3.2995 & & 3.2992 \\
\hline 81.6 & 0.98927 & 3.3223 & & 3.3221 \\
\hline 81.8 & 0.98978 & 3.3458 & & 3.3455 \\
\hline 82 & 0.99027 & 3.3699 & & 3.3696 \\
\hline 82.2 & 0.99075 & 3.3946 & & 3.3942 \\
\hline 82.4 & 0.99122 & 3.4199 & & 3.4196 \\
\hline 82.6 & 0.99167 & 3.4460 & & 3.4456 \\
\hline 82.8 & 0.99211 & 3.4728 & & 3.4724 \\
\hline 83 & 0.99255 & 3.5004 & & 3.4999 \\
\hline 83.2 & 0.99297 & 3.5288 & & 3.5283 \\
\hline 83.4 & 0.99337 & 3.5581 & & 3.5575 \\
\hline 83.6 & 0.99377 & 3.5884 & & 3.5877 \\
\hline 83.8 & 0.99415 & 3.6196 & & 3.6188 \\
\hline 84 & 0.99452 & 3.6519 & & 3.6510 \\
\hline 84.2 & 0.99488 & 3.6852 & & 3.6843 \\
\hline 84.4 & 0.99523 & 3.7198 & & 3.7187 \\
\hline 84.6 & 0.99556 & 3.7557 & & 3.7545 \\
\hline 84.8 & 0.99588 & 3.7930 & & 3.7916 \\
\hline 85 & 0.99619 & 3.8317 & & 3.8302 \\
\hline 85.2 & 0.99649 & 3.8721 & & 3.8704 \\
\hline 85.4 & 0.99678 & 3.9142 & & 3.9122 \\
\hline 85.6 & 0.99705 & 3.9583 & & 3.956 \\
\hline 85.8 & 0.99731 & 4.0044 & & 4.0018 \\
\hline 86 & 0.99756 & 4.0528 & & 4.049 \\
\hline 86.2 & 0.99780 & 4.1037 & & 4.1003 \\
\hline 86.4 & 0.99803 & 4.1574 & & 4.1535 \\
\hline 86.6 & 0.99824 & 4.2142 & & 4.2097 \\
\hline 86.8 & 0.99844 & 4.2744 & & 4.2692 \\
\hline 87 & 0.99863 & 4.3387 & & 4.3325 \\
\hline 87.2 & 0.99881 & 4.4073 & & 4.4001 \\
\hline 87.4 & 0.99897 & 4.4811 & & 4.472 \\
\hline 87.6 & 0.99912 & 4.5609 & & 4.550 \\
\hline 87.8 & 0.99926 & 4.6477 & & 4.635 \\
\hline 88 & 0.99939 & 4.7427 & & 4.727 \\
\hline 88.2 & 0.99951 & 4.8478 & & 4.829 \\
\hline 88.4 & 0.99961 & 4.9654 & & \\
\hline 88.6 & 0.99970 & 5.0988 & & \\
\hline 88.8 & 0.99978 & 5.2527 & & \\
\hline 89 & 0.99985 & 5.4349 & & \\
\hline 89.1 & 0.99988 & 5.5402 & & \\
\hline 89.2 & 0.99990 & 5.6579 & & \\
\hline 89.3 & 0.99993 & 5.7914 & & \\
\hline 89.4 & 0.99995 & 5.9455 & & \\
\hline 89.5 & 0.99996 & 6.1278 & & \\
\hline 89.6 & 0.99998 & 6.3509 & & \\
\hline 89.7 & 0.99999 & 6.6385 & & \\
\hline 89.8 & 0.99999 & 7.0440 & & \\
\hline 89.9 & 1.00000 & 7.7371 & & \\
\hline 90 & 1.00000 & $\infty$ & $-\infty$ & $-\infty$ \\
\hline
\end{tabular}

The values strings in the last two columns of table 1 were canceled when each of the two closed analytic formulas proposed for the approximation of the Legendre complete elliptic integral of the $1^{\text {st }}$ kind $\mathrm{K}(k)$ gives too great relative errors ( $\geq 4 \%$ - also see chapter 3$)$ for being still accepted in the usual mathematical / technical calculus. The same procedure will be applied in case of the next table (no. 2), for the same reason, concerning the accuracy of the values given by each of the other two closed analytic formulas proposed for the approximation of the Legendre complete elliptic integral of the $2^{\text {nd }}$ kind $\mathrm{E}(k)$. The accuracy analysis of the two sets of formulas will be performed in the next chapter (no. 3). In chapter 4 some series representations for the exact functions and for both sets of approximation, as well as for their first order derivatives, will be given.

Table 2. Values of the functions $\mathrm{E}$ (part one)

$\begin{array}{ccccc}\theta\left({ }^{\circ}\right) & k=\sin \theta & \mathrm{E}(k) & \mathrm{E}_{0}(k) & \mathrm{E}_{1}(k) \\ 0 & 0.00000 & 1.5708 & 1.5708 & 1.5708 \\ 1 & 0.01745 & 1.5707 & 1.5707 & 1.5707 \\ 2 & 0.03490 & 1.5703 & 1.5703 & 1.5703 \\ 3 & 0.05234 & 1.5697 & 1.5697 & 1.5697 \\ 4 & 0.06976 & 1.5689 & 1.5689 & 1.5689 \\ 5 & 0.08716 & 1.5678 & 1.5678 & 1.5678 \\ 6 & 0.10453 & 1.5665 & 1.5665 & 1.5665 \\ 7 & 0.12187 & 1.5649 & 1.5649 & 1.5649 \\ 8 & 0.13917 & 1.5632 & 1.5632 & 1.5632 \\ 9 & 0.15643 & 1.5611 & 1.5611 & 1.5611 \\ 10 & 0.17365 & 1.5589 & 1.5589 & 1.5589 \\ 11 & 0.19081 & 1.5564 & 1.5564 & 1.5564 \\ 12 & 0.20791 & 1.5537 & 1.5537 & 1.5537 \\ 13 & 0.22495 & 1.5507 & 1.5507 & 1.5507 \\ 14 & 0.24192 & 1.5476 & 1.5476 & 1.5476 \\ 15 & 0.25882 & 1.5442 & 1.5442 & 1.5442 \\ 16 & 0.27564 & 1.5405 & 1.5405 & 1.5405 \\ 17 & 0.29237 & 1.5367 & 1.5367 & 1.5367 \\ 18 & 0.30902 & 1.5326 & 1.5326 & 1.5326 \\ 19 & 0.32557 & 1.5283 & 1.5283 & 1.5283 \\ 20 & 0.34202 & 1.5238 & 1.5238 & 1.5238 \\ 21 & 0.35837 & 1.5191 & 1.5191 & 1.5191 \\ 22 & 0.37461 & 1.5141 & 1.5141 & 1.5141 \\ 23 & 0.39073 & 1.5090 & 1.5090 & 1.5090 \\ 24 & 0.40674 & 1.5037 & 1.5037 & 1.5037 \\ 25 & 0.42262 & 1.4981 & 1.4981 & 1.4981 \\ 26 & 0.43837 & 1.4924 & 1.4924 & 1.4924 \\ 27 & 0.45399 & 1.4864 & 1.4864 & 1.4864 \\ 28 & 0.46947 & 1.4803 & 1.4803 & 1.4803 \\ 29 & 0.48481 & 1.4740 & 1.4740 & 1.4740 \\ 30 & 0.50000 & 1.4675 & 1.4675 & 1.4675 \\ 31 & 0.51504 & 1.4608 & 1.4608 & 1.4608 \\ 32 & 0.52992 & 1.4539 & 1.4539 & 1.4539 \\ 33 & 0.54464 & 1.4469 & 1.4469 & 1.4469 \\ 34 & 0.55919 & 1.4397 & 1.4397 & 1.4397 \\ 35 & 0.57358 & 1.4323 & 1.4323 & 1.4323 \\ 36 & 0.58779 & 1.4248 & 1.4248 & 1.4248 \\ 37 & 0.60182 & 1.4171 & 1.4171 & 1.4171 \\ 38 & 0.61566 & 1.4092 & 1.4093 & 1.4092 \\ 39 & 0.62932 & 1.4013 & 1.4013 & 1.4013 \\ 40 & 0.64279 & 1.3931 & 1.3932 & 1.3931\end{array}$


Table 2. Values of the functions E (part two)

$\begin{array}{ccccc}41 & 0.65606 & 1.3849 & 1.3849 & 1.3849 \\ 42 & 0.66913 & 1.3765 & 1.3765 & 1.3765 \\ 43 & 0.68200 & 1.3680 & 1.3680 & 1.3680 \\ 44 & 0.69466 & 1.3594 & 1.3594 & 1.3594 \\ 45 & 0.70711 & 1.3506 & 1.3507 & 1.3506 \\ 46 & 0.71934 & 1.3418 & 1.3419 & 1.3418 \\ 47 & 0.73135 & 1.3329 & 1.3330 & 1.3329 \\ 48 & 0.74314 & 1.3238 & 1.3239 & 1.3238 \\ 49 & 0.75471 & 1.3147 & 1.3148 & 1.3147 \\ 50 & 0.76604 & 1.3055 & 1.3057 & 1.3055 \\ 51 & 0.77715 & 1.2963 & 1.2964 & 1.2963 \\ 52 & 0.78801 & 1.2870 & 1.2872 & 1.2870 \\ 53 & 0.79864 & 1.2776 & 1.2778 & 1.2776 \\ 54 & 0.80902 & 1.2681 & 1.2684 & 1.2681 \\ 55 & 0.81915 & 1.2587 & 1.2590 & 1.2587 \\ 56 & 0.82904 & 1.2492 & 1.2496 & 1.2492 \\ 57 & 0.83867 & 1.2397 & 1.2401 & 1.2397 \\ 58 & 0.84805 & 1.2301 & 1.2307 & 1.2301 \\ 59 & 0.85717 & 1.2206 & 1.2212 & 1.2206 \\ 60 & 0.86603 & 1.2111 & 1.2118 & 1.2111 \\ 61 & 0.87462 & 1.2015 & 1.2024 & 1.2015 \\ 62 & 0.88295 & 1.1920 & 1.1930 & 1.1920 \\ 63 & 0.89101 & 1.1826 & 1.1838 & 1.1826 \\ 64 & 0.89879 & 1.1732 & 1.1745 & 1.1732 \\ 65 & 0.90631 & 1.1638 & 1.1654 & 1.1638 \\ 66 & 0.91355 & 1.1545 & 1.1564 & 1.1545 \\ 67 & 0.92050 & 1.1453 & 1.1475 & 1.1453 \\ 68 & 0.92718 & 1.1362 & 1.1387 & 1.1362 \\ 69 & 0.93358 & 1.1272 & 1.1301 & 1.1273 \\ 70 & 0.93969 & 1.1184 & 1.1217 & 1.1184 \\ 70.5 & 0.94264 & 1.1140 & 1.1176 & 1.1140 \\ 71 & 0.94552 & 1.1096 & 1.1135 & 1.1096 \\ 71.5 & 0.94832 & 1.1053 & & 1.1053 \\ 72 & 0.95106 & 1.1011 & & 1.1011 \\ 72.5 & 0.95372 & 1.0968 & & 1.0968 \\ 73 & 0.95630 & 1.0927 & & 1.0927 \\ 73.5 & 0.95882 & 1.0885 & & 1.0885 \\ 74 & 0.96126 & 1.0844 & & 1.0844 \\ 74.5 & 0.96363 & 1.0804 & & 1.0804 \\ 75 & 0.96593 & 1.0764 & & 1.0764 \\ 75.5 & 0.96815 & 1.0725 & & 1.0725 \\ 76 & 0.97030 & 1.0686 & & 1.0686 \\ 76.5 & 0.97237 & 1.0648 & & 1.0648 \\ 77 & 0.97437 & 1.0611 & & 1.0611 \\ 77.5 & 0.97630 & 1.0574 & & 1.0574 \\ 78 & 0.97815 & 1.0538 & & 1.0538 \\ 78.5 & 0.97992 & 1.0502 & & 1.0503 \\ 79 & 0.98163 & 1.0468 & & 1.0468 \\ 79.5 & 0.98325 & 1.0434 & & 1.0435 \\ 80.2 & 0.98481 & 1.0401 & & 1.0402 \\ 80.4 & 0.98541 & 1.0388 & & 1.0389 \\ 80.6 & 0.98650 & 1.0375 & & 1.0376 \\ 80.8 & 0.98714 & 1.0363 & & 1.0364 \\ & & & & 1.0351\end{array}$

\begin{tabular}{|c|c|c|c|c|}
\hline 81 & 0.98769 & 1.0338 & & 1.0339 \\
\hline 81.2 & 0.98823 & 1.0326 & & 1.0327 \\
\hline 81.4 & 0.98876 & 1.0314 & & 1.0315 \\
\hline 81.6 & 0.98927 & 1.0302 & & 1.0303 \\
\hline 81.8 & 0.98978 & 1.0290 & & 1.0292 \\
\hline 82 & 0.99027 & 1.0278 & & 1.0280 \\
\hline 82.2 & 0.99075 & 1.0267 & & 1.0269 \\
\hline 82.4 & 0.99122 & 1.0256 & & 1.0258 \\
\hline 82.6 & 0.99167 & 1.0245 & & 1.0247 \\
\hline 82.8 & 0.99211 & 1.0234 & & 1.0236 \\
\hline 83 & 0.99255 & 1.0223 & & 1.0226 \\
\hline 83.2 & 0.99297 & 1.0213 & & 1.0215 \\
\hline 83.4 & 0.99337 & 1.0202 & & 1.0205 \\
\hline 83.6 & 0.99377 & 1.0192 & & 1.0196 \\
\hline 83.8 & 0.99415 & 1.0182 & & 1.0186 \\
\hline 84 & 0.99452 & 1.0172 & & 1.0176 \\
\hline 84.2 & 0.99488 & 1.0163 & & 1.0167 \\
\hline 84.4 & 0.99523 & 1.0153 & & 1.0158 \\
\hline 84.6 & 0.99556 & 1.0144 & & 1.0150 \\
\hline 84.8 & 0.99588 & 1.0135 & & 1.0141 \\
\hline 85 & 0.99619 & 1.0127 & & 1.0133 \\
\hline 85.2 & 0.99649 & 1.0118 & & 1.0125 \\
\hline 85.4 & 0.99678 & 1.0110 & & 1.0118 \\
\hline 85.6 & 0.99705 & 1.0102 & & 1.0110 \\
\hline 85.8 & 0.99731 & 1.0094 & & 1.0103 \\
\hline 86 & 0.99756 & 1.0086 & & 1.0097 \\
\hline 86.2 & 0.99780 & 1.0079 & & 1.0091 \\
\hline 86.4 & 0.99803 & 1.0072 & & 1.0085 \\
\hline 86.6 & 0.99824 & 1.0065 & & 1.0080 \\
\hline 86.8 & 0.99844 & 1.0059 & & 1.0075 \\
\hline 87 & 0.99863 & 1.0053 & & 1.0071 \\
\hline 87.2 & 0.99881 & 1.0047 & & 1.0067 \\
\hline 87.4 & 0.99897 & 1.0041 & & 1.0064 \\
\hline 87.6 & 0.99912 & 1.0036 & & 1.0062 \\
\hline 87.8 & 0.99926 & 1.0031 & & 1.0060 \\
\hline 88 & 0.99939 & 1.0026 & & 1.0060 \\
\hline 88.2 & 0.99951 & 1.0021 & & 1.0061 \\
\hline 88.4 & 0.99961 & 1.0017 & & \\
\hline 88.6 & 0.99970 & 1.0014 & & \\
\hline 88.8 & 0.99978 & 1.0010 & & \\
\hline 89 & 0.99985 & 1.0008 & & \\
\hline 89.1 & 0.99988 & 1.0006 & & \\
\hline 89.2 & 0.99990 & 1.0005 & & \\
\hline 89.3 & 0.99993 & 1.0004 & & \\
\hline 89.4 & 0.99995 & 1.0003 & & \\
\hline 89.5 & 0.99996 & 1.0002 & & \\
\hline 89.6 & 0.99998 & 1.0001 & & \\
\hline 89.7 & 0.99999 & 1.0001 & & \\
\hline 89.8 & 0.99999 & 1.0000 & & \\
\hline 89.9 & 1.00000 & 1.0000 & & \\
\hline 90 & 1.00000 & 1.0000 & 1.1781 & 1.1781 \\
\hline
\end{tabular}

In the comparative tables 1 and 2 , the $4 D$ (four decimal digit) exact values of both Legendre complete elliptic integrals reproduced from special functions tables [6] (tab. 29, p. 117), as well as their $4 D$ approximate values obtained by applying the two sets of closed 
analytic formulas were given (all versus the respective elliptic integrals modulus $k=\sin \theta$ ). It is to be noticed that both sets of approximate formulas are not given by spline or regression functions, but by asymptotic expressions, these ones having a remarkable simplicity (see, e.g: the $2^{\text {nd }}$ form of $E_{0}(k)$, suggested by Peano's law on ellipse's perimeter, all newly found formulas in $k / k^{\prime}$ do not need any mathematical table, being purely algebraic) and accuracy (see table 3). The identity with the exact functions is satisfied for the left domain's end $k=0\left(\theta=0^{\circ}\right)$. The $2^{\text {nd }} \operatorname{set}\left(\mathrm{K}_{1}, \mathrm{E}_{1}\right)$, atthough a bit more intricate, gives more accurate values than the $1^{\mathrm{s}}$ one $\left(\mathrm{K}_{0}, \mathrm{E}_{0}\right)$ and arrives more closely to the right domain's end $k=1\left(\theta=90^{\circ}\right)$.

\section{The accuracy of the two sets of formulas}

Let us define the following relative error functions: $\varepsilon_{\mathrm{K}_{0}}(k)=\mathrm{K}_{0}(k) / \mathrm{K}(k)-1 ; \quad \varepsilon_{\mathrm{K}_{1}}(k)=\mathrm{K}_{1}(k) / \mathrm{K}(k)-1$, $\varepsilon_{\mathrm{E}_{0}}(k)=\mathrm{E}_{0}(k) / \mathrm{E}(k)-1 ; \quad \varepsilon_{\mathrm{E}_{1}}(k)=\mathrm{E}_{1}(k) / \mathrm{E}(k)-1$, for both sets of approximation of the $1^{\text {st }}$ and $2^{\text {nd }}$ kind integrals, resp. Their values are given in table 3 , expressed in thousandths $(\%)$. These errors were calculated for the $1^{\text {st }} \operatorname{set}\left(\mathrm{K}_{0}, \mathrm{E}_{0}\right)$ only in the field $\theta \in\left[54^{\circ}, 71^{\circ}\right]$ of the domain, with an increment of $1^{\circ}$, while for the $2^{\text {nd }}$ set $\left(\mathrm{K}_{1}, \mathrm{E}_{1}\right)$ only in the field $\theta \in\left[84^{\circ} .8\right.$, $88^{\circ} .2$ ], with an increment of $0^{\circ} .2$, like in tables $1 \& 2$.

Table 3. Relative errors $\varepsilon$ distribution

\begin{tabular}{|c|c|c|c|c|c|}
\hline$\theta\left(^{\circ}\right)$ & $k=\sin \theta$ & $\varepsilon_{\mathrm{K} 0}(\% 0)$ & $\varepsilon_{\mathrm{K}_{1}}(\%)$ & $\varepsilon_{\mathrm{E} 0}(\% o)$ & $\varepsilon_{\mathrm{E}_{1}}(\% 0)$ \\
\hline 54 & 0.80902 & -0.250 & & +0.255 & \\
\hline 55 & 0.81915 & -0.272 & & +0.243 & \\
\hline 56 & 0.82904 & -0.353 & & +0.293 & \\
\hline 57 & 0.83867 & -0.420 & & +0.334 & \\
\hline 58 & 0.84805 & -0.497 & & +0.454 & \\
\hline 59 & 0.85717 & -0.558 & & +0.502 & \\
\hline 60 & 0.86603 & -0.669 & & +0.566 & \\
\hline 61 & 0.87462 & -0.799 & & +0.742 & \\
\hline 62 & 0.88295 & -0.961 & & +0.874 & \\
\hline 63 & 0.89101 & -1.118 & & +0.973 & \\
\hline 64 & 0.89879 & -1.366 & & +1.135 & \\
\hline 65 & 0.90631 & -1.619 & & +1.377 & \\
\hline 66 & 0.91355 & -1.918 & & +1.627 & \\
\hline 67 & 0.92050 & -2.299 & & +1.900 & \\
\hline 68 & 0.92718 & -2.709 & & +2.215 & \\
\hline 69 & 0.93358 & -3.253 & & +2.573 & \\
\hline 70 & 0.93969 & -3.907 & & +2.959 & \\
\hline 71 & 0.94552 & -4.642 & & +3.525 & \\
\hline & & - & & . & \\
\hline 84.8 & 0.99588 & - & -0.369 & - & +0.607 \\
\hline 85 & 0.99619 & - & -0.396 & - & +0.592 \\
\hline 85.2 & 0.99649 & - & -0.451 & - & +0.705 \\
\hline 85.4 & 0.99678 & - & -0.500 & - & +0.748 \\
\hline 85.6 & 0.99705 & - & -0.582 & - & +0.823 \\
\hline 85.8 & 0.99731 & - & -0.652 & - & +0.932 \\
\hline 86 & 0.99756 & - & -0.737 & - & +1.076 \\
\hline 86.2 & 0.99780 & - & -0.832 & - & +1.160 \\
\hline 86.4 & 0.99803 & - & -0.945 & - & +1.284 \\
\hline 86.6 & 0.99824 & - & -1.077 & - & +1.453 \\
\hline
\end{tabular}

$\begin{array}{cccccc}86.8 & 0.99844 & - & -1.214 & - & +1.571 \\ 87 & 0.99863 & - & -1.421 & - & +1.743 \\ 87.2 & 0.99881 & - & -1.626 & - & +1.976 \\ 87.4 & 0.99897 & - & -1.894 & - & +2.275 \\ 87.6 & 0.99912 & - & -2.234 & - & +2.553 \\ 87.8 & 0.99926 & - & -2.655 & - & +2.922 \\ 88 & 0.99939 & - & -3.156 & - & +3.397 \\ 88.2 & 0.99951 & - & -3.808 & - & +4.004\end{array}$

The relative errors strings are stopped for values $\geq 4 \%$. One can see that both sets given in chapter 2 have a much lesser relative error for $\mathrm{K}(k)$ than the well-known asymptotic expression: $\mathrm{K}(k) \approx \pi / 2+(\pi / 8)\left[k^{2} /\left(1-\mathrm{k}^{2}\right)\right]-(\pi / 16)\left[k^{4} /\left(1-\mathrm{k}^{4}\right)\right]$, with a relative precision of $3 \cdot 10^{-4}$ for $k<0.5\left(\theta<30^{\circ}\right)$, only.

\section{Comparative series representations; Legendre's functional relation}

Expanding into power series, one obtains for the complete elliptic integrals the set of representations below ([5] - [7]):

$$
\begin{aligned}
& \mathrm{K}(k)=\frac{\pi}{2}\left(1+\frac{1}{4} k^{2}+\frac{9}{64} k^{4}+\frac{25}{256} k^{6}+\frac{1225}{16384} k^{8}+\frac{3969}{65536} k^{10}\right. \\
& \left.+\frac{53361}{1048576} k^{12}+\frac{184041}{4194304} k^{14}+\frac{41409225}{1073741824} k^{16}+\ldots\right) \\
& =\frac{\pi}{2}\left\{1+\sum_{n=1}^{\infty}\left[\frac{1 \cdot 3 \cdot \ldots(2 n-1)}{2 \cdot 4 \cdot \ldots \cdot 2 n}\right]^{2} k^{2 n}\right\}=\frac{\pi}{2}\left\{1+\sum_{n=1}^{\infty}\left[\frac{(2 n-1) ! !}{2^{n} n !}\right]^{2} k^{2 n} ;\right. \\
& \mathrm{E}(k)=\frac{\pi}{2}\left(1-\frac{1}{4} k^{2}-\frac{3}{64} k^{4}-\frac{5}{256} k^{6}-\frac{175}{16384} k^{8}-\frac{441}{65536} k^{10}\right. \\
& \left.-\frac{4851}{1048576} k^{12}-\frac{14157}{4194304} k^{14}-\frac{2760615}{1073741824} k^{16}-\ldots\right) \\
& =\frac{\pi}{2}\left\{1-\sum_{n=1}^{\infty}\left[\frac{1 \cdot 3 \cdot . .(2 n-1)}{2 \cdot 4 \cdot \ldots \cdot 2 n}\right]^{2} \frac{k^{2 n}}{2 n-1}\right\}=\frac{\pi}{2}\left\{1-\sum_{n=1}^{\infty}\left[\frac{(2 n-1) ! !}{2^{n} n !}\right] \frac{k^{2 n}}{2 n-1}\right\} .
\end{aligned}
$$

Proceeding in the same manner, we get for the $1^{\text {st }}$ set (the most inaccurate) of approximate functions the expansions

$$
\begin{aligned}
& \mathrm{K}_{0}(k)=\frac{\pi}{2}\left(1+\frac{1}{4} k^{2}+\frac{9}{64} k^{4}+\frac{25}{256} k^{6}+\frac{1222}{16384} k^{8}+\ldots\right) ; \\
& \mathrm{E}_{0}(k)=\frac{\pi}{2}\left(1-\frac{1}{4} k^{2}-\frac{3}{64} k^{4}-\frac{5}{256} k^{6}-\frac{172}{16384} k^{8}-\ldots\right),
\end{aligned}
$$

for the $2^{\text {nd }}$ set being practically identical with the exact ones $\mathrm{K}_{1}(k)=\frac{\pi}{2}\left(1+\frac{1}{4} k^{2}+\frac{9}{64} k^{4}+\frac{25}{256} k^{6}+\frac{1225}{16384} k^{8}+\frac{3969}{65536} k^{10}\right.$ $\left.+\frac{53361}{1048576} k^{12}+\frac{184041}{4194304} k^{14}+\frac{41409222}{1073741824} k^{16}+\ldots\right)$

$\mathrm{E}_{1}(k)=\frac{\pi}{2}\left(1-\frac{1}{4} k^{2}-\frac{3}{64} k^{4}-\frac{5}{256} k^{6}-\frac{175}{16384} k^{8}-\frac{441}{65536} k^{10}\right.$ $\left.-\frac{4851}{1048576} k^{12}-\frac{14157}{4194304} k^{14}-\frac{2760606}{1073741824} k^{16}-\ldots\right)$.

The difference with respect to the expansions of the exact functions $(\mathrm{K}, \mathrm{E})$ begins at the terms in $k^{8}$ for the $1^{\mathrm{st}}$ set of approximation $\left(\mathrm{K}_{0}, \mathrm{E}_{0}\right)$, and at the terms in $k^{16}$ for the $2^{\text {nd }}$ one $\left(K_{1}, E_{1}\right)$. For the $1^{\text {st }}$ derivatives of $K$, E we get 


$$
\begin{aligned}
& \frac{d \mathrm{~K}(k)}{d k}=\frac{\mathrm{E}(k)}{k\left(1-k^{2}\right)}-\frac{\mathrm{K}(k)}{k}=\frac{\pi}{4} k\left(1+\frac{9}{8} k^{2}+\frac{75}{64} k^{4}+\frac{1225}{1024} k^{6}\right. \\
& \left.+\frac{19845}{16384} k^{8}+\frac{160083}{131072} k^{10}+\frac{1288287}{1048576} k^{12}+\frac{41409225}{33554432} k^{14}+\right) \\
& =\frac{\pi}{4} \sum_{n=1}^{\infty}\left[\frac{1 \cdot 3 \cdot \ldots(2 n-1)}{2 \cdot 4 \cdot \ldots \cdot 2 n}\right]^{2} n k^{2 n-1}=\frac{\pi}{4} \sum_{n=1}^{\infty}\left[\frac{(2 n-1) ! !}{2^{n-1} n !}\right]^{2} n k^{2 n-1} ; \\
& \frac{d \mathrm{E}(k)}{d k}=\frac{\mathrm{E}(k)-\mathrm{K}(k)}{k}=-\frac{\pi}{4} k\left(1+\frac{3}{8} k^{2}+\frac{15}{64} k^{4}+\frac{175}{1024} k^{6}\right. \\
& \left.+\frac{2205}{16384} k^{8}+\frac{14553}{131072} k^{10}+\frac{99099}{1048576} k^{12}+\frac{2760615}{33554432} k^{14}+\ldots\right) \\
& =-\frac{\pi}{4} \sum_{n=1}^{\infty}\left[\frac{1 \cdot 3 \cdot \ldots(2 n-1)}{2 \cdot 4 \cdot \ldots \cdot 2 n}\right]^{2} \frac{n k^{2 n-1}}{2 n-1}=-\frac{\pi}{4} \sum_{n=1}^{\infty}\left[\frac{(2 n-1) ! !}{2^{n-1} n !}\right]^{2} \frac{n k^{2 n-1}}{2 n-1} .
\end{aligned}
$$

Applying the previous two exact relations and using the four definitions from chapter 2 one gets the expansions: $\left[\frac{d \mathrm{~K}(k)}{d k}\right]_{0}=\frac{\pi}{4} k\left(1+\frac{9}{8} k^{2}+\frac{75}{64} k^{4}+\frac{1225.75}{1024} k^{6}+\ldots\right) ;$
$\left[\frac{d \mathrm{E}(k)}{d k}\right]_{0}=-\frac{\pi}{4} k\left(1+\frac{3}{8} k^{2}+\frac{15}{64} k^{4}+\frac{174.25}{1024} k^{6}+\ldots\right)$, for the $1^{\text {st }}$ set of approximate functions $\left(\mathrm{K}_{0}, \mathrm{E}_{0}\right)$, and resp. $\left[\frac{d \mathrm{~K}(k)}{d k}\right]_{1}=\frac{\pi}{4} k\left(1+\frac{9}{8} k^{2}+\frac{75}{64} k^{4}+\frac{1225}{1024} k^{6}+\frac{19845}{16384} k^{8}\right.$ $\left.+\frac{160083}{131072} k^{10}+\frac{1288287}{1048576} k^{12}+\frac{41409226.125}{33554432} k^{14}+\ldots\right)$; $\left[\frac{d \mathrm{E}(k)}{d k}\right]_{1}=-\frac{\pi}{4} k\left(1+\frac{3}{8} k^{2}+\frac{15}{64} k^{4}+\frac{175}{1024} k^{6}+\frac{2205}{16384} k^{8}\right.$ $\left.+\frac{14553}{131072} k^{10}+\frac{99099}{1048576} k^{12}+\frac{276061425}{33554432} k^{14}+\ldots\right)$, for the $2^{\text {nd }}$ set of approximate functions $\left(\mathrm{K}_{1}, \mathrm{E}_{1}\right)$. The difference with respect to the expansions of the $1^{\text {st }}$ derivatives of the exact functions $(\mathrm{K}, \mathrm{E})$ begins at the terms in $k^{7}$ for the $1^{\text {st }}$ set, and at the terms in $k^{15}$ for the $2^{\text {nd }}$ one, so much lesser than that for the expansions of the respective sets $\left(\mathrm{K}_{0,1}, \mathrm{E}_{0,1}\right)$. One can also easily find the analytic expressions and series representations for the $2^{\text {nd }}$ derivatives of all $\mathrm{K}, \mathrm{K}_{0,1}, \mathrm{E}, \mathrm{E}_{0,1}$, with similar results, but a lesser precision than for $\mathrm{K}, \mathrm{E}, \mathrm{K}, \mathrm{E}$ '. Besides the above definitions of the derivatives $\mathrm{K}^{\prime}(=\mathrm{dK} / \mathrm{d} k)$, $\mathrm{E}^{\prime}(=\mathrm{dE} / \mathrm{d} k)$, there is a useful functional relation (Legendre's): $\mathrm{K}(k) \cdot \mathrm{E}\left(k^{\prime}\right)+\mathrm{E}(k) \cdot \mathrm{K}\left(k^{\prime}\right)-\mathrm{K}(k) \cdot \mathrm{K}\left(k^{\prime}\right)=\pi / 2$.

\section{Graphic comparison}

The variation curves of Legendre complete elliptic integrals, as well as that of the two sets of closed analytic functions are graphically represented in the comparative figures 1 and 2, all vs. $\theta$, in sexagesimal degrees, and given by $\theta=\sin ^{-1} k$. In both figures the exact functions $\mathrm{K}(k), \mathrm{E}(k)$ were represented by solid (continuous) black lines, the $1^{\text {st }}$ set of approximation $\left[\mathrm{K}_{0}(k), \mathrm{E}_{0}(k)\right]$ by dashed black lines, and the $2^{\text {nd }}$ set of approximation $\left[\mathrm{K}_{1}(k), \mathrm{E}_{1}(k)\right]$ by solid red lines. At $k=1$ the graphs of all $\mathrm{K}_{0,1}(k)$ fall to $(-\infty)$; the graphs of all $\mathrm{E}_{0,1}(k)$ pass through $(1,3 \pi / 8)$.

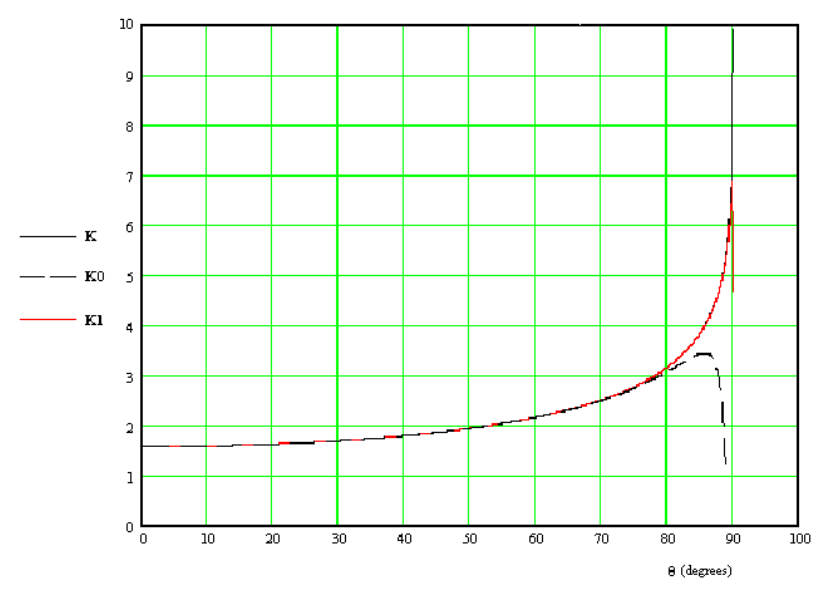

Fig. 1. Comparison of $\mathrm{K}(k)$ with the closed analytic functions $\mathrm{K}_{0}(k), \mathrm{K}_{1}(k)$; also see the end of remark 1 in the appendix

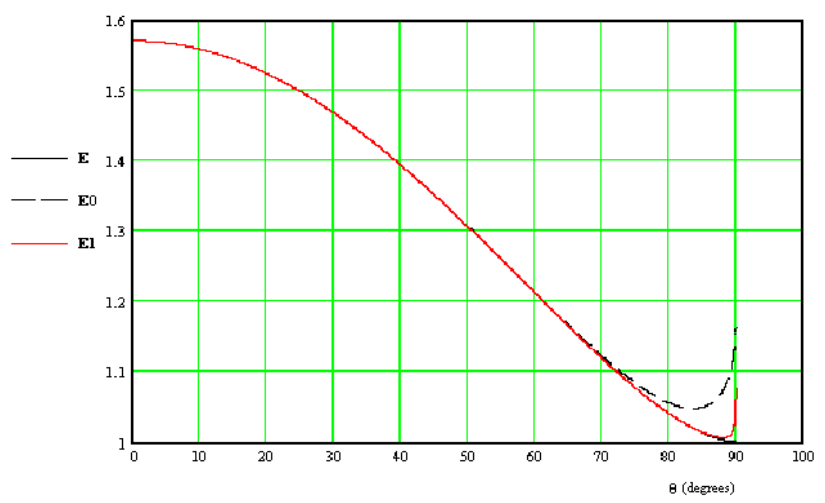

Fig. 2. Comparison of $\mathrm{E}(k)$ with the closed analytic functions $\mathrm{E}_{0}(k), \mathrm{E}_{1}(k)$; also see the end of remark 1 in the appendix

\section{Conclusions}

As for simplicity, the formulas in $k / k^{\prime}$ do not need mathematical tables (are purely algebraic). As for accuracy, in mathematical/ technical applications, it must use the $1^{\mathrm{st}}$ set until $\theta=70^{\circ} .5(\mathrm{k}=$ 0.94264) only, and (for a better accuracy or a greater upper limit of the validity domain $)$ the $2^{\text {nd }}$ set, until $\theta=88^{\circ} .2(k=0.99951)$.

\section{Notes; other methods; future research}

Without the comparative tables 1 and 2, the errors table becoming so table 1, this work was published previously in a proceedings volume (scientific bulletin), in Romanian [8]. For the first English version of this work see [9], [10]. Approximations for the complete elliptic integrals based on the trapezoidal-type numerical integration formulas discussed in [11], are developed in [12], [13] (a mixed numerical-analytic method). Newer formulas (using $\Gamma$ function-not an elementary, but a special one, like K\&E, even if these formulas are the most accurate) are in [14], [15]; as stated in their abstracts, the works [9], [14] do not have the same goal. An original fast converging recurrent-iterative scheme to get a $3^{\text {rd }}$ (and higher) set of closed analytic formulas (seemingly intricate) with desired accuracy is given in article's appendix. This article represents a fully extended version of the paper [9]. Notable special functions suitable for applying such an approximate method of calculation are: $\mathrm{Si}(\mathrm{x}) ; \mathrm{Ci}(\mathrm{x})$; $\operatorname{Ei}(\mathrm{x}) ; \mathrm{li}(\mathrm{x})$. 
References:

[1] Legendre, A. M., Tables of the complete and incomplete elliptic integrals. Reissued (from tome II of Legendre's Traité des fonctions elliptiques, Paris, 1825) by K. Pearson, London, 1934. [2] Heuman, C. A., Tables of complete elliptic integrals, J. Math. Physics, 20, pp. 127 - 206, 336, 1941; https:// onlinelibrary.wiley.com/doi/epdf/10.1002/sapm1941201127. [3] Hayashi, K., Tafeln der Besselschen, Theta-, Kugelund anderen Funktionen, Berlin, 1930; Table errata no. 518 (pp. 670 - 672) by: O. Skovgaard and M. Helmer Petersen; (A. Fletcher, J. C. P. Miller, L. Rosenhead \& L. J. Comrie), Math. Comp., Vol. 29, No. 130 (Apr. 1975). [4] Hayashi, K., Tafeln für die Differenzenrechnung sowie für die Hyperbel-, Besselschen, elliptischen und anderen Funktionen, Berlin, 1933; Table errata no. 517 (p. 670) by: O. Skovgaard and M. Helmer Petersen; (A. Fletcher), Math. Comp., Vol. 29, No. 130 (Apr. 1975). [5] Jahnke, E., Emde, F., Tables of Functions with Formulae and Curves, Dover Publications, New York, 1943; Fourth Edition, 1945; (translated into Russian: Е. Янке и Ф. Эмде, Таблищы функии с формулами и кривыми, Физматгиз, Москва - Ленинград, 1959;) [6] Jahnke, E., Emde, F., Lösch, F., Tafeln höherer Funktionen, sechste Auflage. Neubearbeitet von F. Lösch, B. G. Teubner Verlagsgesellschaft, Stuttgart, 1960, 1961; https://doi.org/10.1002/zamm.19610410619; (translated into Russian: Е. Янке, Ф. Эмде, Ф. Лёш, Специальнье функиии - формуль, графики, таблиць, ред.: Л. И. Седов, Наука, Москва, 1964; https://ikfia.ysn.ru/ wp-content/uploads/2018/01/JankeEmdeLyosh1964ru.pdf). [7] Gradshteyn, I. S., Ryzhik, I. M., Table of Integrals, Series, and Products. Fourth Edition Prepared by Yu. V. Geronimus / M. Yu. Tseytlin, Academic Press, New York, London, 1965; Translated from Russian by Scripta Technica, Inc.; Seventh Edition, 2007; Eds.: A. Jeffrey, D. Zwillinger; (Russian, German, Polish, English, Japanese \& Chinese eds.;) http://fisica.ciens.ucv.ve/ svincenz/TISPISGIMR.pdf.

\section{Appendix - A fast converging recurrent- iterative scheme to get a $3^{\text {rd }}$ (and higher) set of analytic formulas with desired accuracy} The formulas for transforming the modulus (Landen, [16, [17]) are:

$$
\mathrm{K}(k)=\frac{2}{1+\sqrt{1-k^{2}}} \mathrm{~K}\left(\frac{1-\sqrt{1-k^{2}}}{1+\sqrt{1-k^{2}}}\right)=\frac{2}{1+k^{\prime}} \mathrm{K}\left(\frac{1-k^{\prime}}{1+k^{\prime}}\right) \text {, }
$$

or : $\mathrm{K}(\theta)=\mathrm{K}\left[\tan ^{2}(\theta / 2)\right] / \cos ^{2}(\theta / 2)$, and, respectively :

$\mathrm{E}(k)=\left(1+\sqrt{1-k^{2}}\right) \mathrm{E}\left(\frac{1-\sqrt{1-k^{2}}}{1+\sqrt{1-k^{2}}}\right)-\sqrt{1-k^{2}} \mathrm{~K}(k)=$

$\left(1+k^{\prime}\right) \mathrm{E}\left[\left(1-k^{\prime}\right) /\left(1+k^{\prime}\right)\right]-k^{\prime} \mathrm{K}(k)$, with $k^{\prime}=\left(1-k^{2}\right)^{1 / 2}$, or: $\mathrm{E}(\theta)=2 \cos ^{2}(\theta / 2) \cdot \mathrm{E}\left[\tan ^{2}(\theta / 2)\right]-\cos \theta \cdot \mathrm{K}(\theta)$,

(passing from $k$ to $k_{1}=(1-k) /(1+k) \leq k$ and from $\theta$ to $\theta_{1}=$ $\sin ^{-1}\left[\tan ^{2}(\theta / 2)\right] \leq \theta ; k_{1}=k\left(\theta_{1}=\theta\right)$, for: $\left.k=0 ; 1(\theta=0 ; \pi / 2)\right)$, which can be transcribed in recurrent form, as follows:
[8] Selescu, R., Formule analitice închise pentru aproximarea integralelor eliptice complete de speța întâia şi a doua ale lui Legendre, Buletinul Ştiințific al Sesiunii Naționale de Comunicări Ştiințifice, Academia Forțelor Aeriene "Henri Coandă" \& Centrul Regional pentru Managementul Resurselor de Apărare, Editura Academiei Forțelor Aeriene "Henri Coandă", Braşov, 1 - 2 Noiembrie 2002; Vol. MATEMATICA - INFORMATICA, Anul III, Nr. 2 (14), (ISSN 1453-0139), pp. 37 - 44; (in Romanian). [9] Selescu, R., Closed Analytic Formulas for the Approximation of the Legendre Complete Elliptic Integrals of the First and Second Kinds, International Journal of Mathematical and Computational Methods, Vol. 21, pp. 49 -55, 21 May 2021; http://www.iaras.org/iaras/journals/jimcm. [10] Selescu, R., Closed Analytic Formulas for the Approximation of the Legendre Complete Elliptic Integrals of the First and Second Kinds, International Journal of Pure Mathematics-NAUN, Vol. 8, pp. 23 -28, DOI: 10.46300/ 91019.2021.8.2,2021; https:/www.naun.org/cmsaction?id=23293. [11] Luke, Y. L., Simple formulas for the evaluation of some higher transcendental functions, J. Math. Physics, v. 34, pp. 298 - 307, 1956, MR 17, \# 1138. [12] Luke, Y. L., Approximations for Elliptic Integrals, Math. Comp., Vol. 22, No. 103 (Jul. 1968),pp. 627-634,MR 17,\#2412; AMS; https://ams.org/journals/mcom/1968-22-103/S02255718-1968-0226825-3/S0025-5718-1968-0226825-3.pdf. [13] Luke, Y. L., Further Approximation for Elliptic Integrals, Math. Comp., Vol. 24, No. 109 (Jan. 1970), pp. 191 - 198, AMS; htpps:// ams.org/journals/mcom/1970-24-109/S00255719-1970-0258243-5/S0025-5719-1970-0258243-5.pdf.

[14] Bagis, N., Formulas for the approximation of the complete Elliptic Integrals, https:/arxiv.org/abs/1104.4798v1 [math.GM], 6 pages (pp. 1-6), 25 April 2011, Comell University, preprint. [15] Bagis, N., Formulas for the Approximation of the Complete Elliptic Integrals, International Mathematical Forum, Vol. 7, no. 55, pp. 2719-2725, 2012; http:/www.m-hikari.com/imf/imf2012/53-56-2012/bagisIMF53-56-2012.pdf; (supersedes [14]).

$\mathrm{K}_{2}(k)=\frac{2}{1+\sqrt{1-k^{2}}} \mathrm{~K}_{1}\left(\frac{1-\sqrt{1-k^{2}}}{1+\sqrt{1-k^{2}}}\right)=\frac{2}{1+k^{\prime}} \mathrm{K}_{1}\left(\frac{1-k^{\prime}}{1+k^{\prime}}\right)$, or: $\mathrm{K}_{2}(\theta)=\mathrm{K}_{1}\left[\tan ^{2}(\theta / 2)\right] / \cos ^{2}(\theta / 2)$, and, respectively: $\mathrm{E}_{2}(k)=\left(1+\sqrt{1-k^{2}}\right) \mathrm{E}_{1}\left(\frac{1-\sqrt{1-k^{2}}}{1+\sqrt{1-k^{2}}}\right)-\sqrt{1-k^{2}} \mathrm{~K}_{2}(k)=$ $=\left(1+k^{\prime}\right) \mathrm{E}_{1}\left(\frac{1-k^{\prime}}{1+k^{\prime}}\right)-\frac{2 k^{\prime}}{1+k^{\prime}} \mathrm{K}_{1}\left(\frac{1-k^{\prime}}{1+k^{\prime}}\right), \quad$ or: $\mathrm{E}_{2}(\theta)=$ $2 \cos ^{2}(\theta / 2) \mathrm{E}_{1}\left[\tan ^{2}(\theta / 2)\right]-\left[\cos \theta / \cos ^{2}(\theta / 2)\right] \mathrm{K}_{1}\left[\tan ^{2}(\theta / 2)\right]$, expressing the $3^{\text {rd }} \operatorname{set}\left(\mathrm{K}_{2}, \mathrm{E}_{2}\right)$ in function of the $2^{\text {nd }}$ one $\left(\mathrm{K}_{1}\right.$, $\mathrm{E}_{1}$ ), so starting a recurrent-iterative scheme; it allows writing for the $(\mathrm{n}+1)^{\text {th }}$ set : $\mathrm{K}_{\mathrm{n}}(k)=\frac{2}{1+k^{\prime}} \mathrm{K}_{\mathrm{n}-1}\left(\frac{1-k^{\prime}}{1+k^{\prime}}\right)$, and $\mathrm{E}_{\mathrm{n}}(k)=\left(1+k^{\prime}\right) \mathrm{E}_{\mathrm{n}-1}\left(\frac{1-k^{\prime}}{1+k^{\prime}}\right)-\frac{2 k^{\prime}}{1+k^{\prime}} \mathrm{K}_{\mathrm{n}-1}\left(\frac{1-k^{\prime}}{1+k^{\prime}}\right)$, resp. 
Starting from the newly found closed analytic formulas, which connect the $3^{\text {rd }}$ set $\left(K_{2}, E_{2}\right)$ with the $2^{\text {nd }}$ one $\left(K_{1}, E_{1}\right)$, by applying the new recurrent-iterative scheme previously presented, the comparative tables 1 and 2 from chapter 2 were remade, suppressing the column " $k=\sin \theta$ ", and inserting the new columns " $\mathrm{K}_{2}(k)$ " and " $\mathrm{E}_{2}(k)$ " with $4 D$ approximate values, resp., so getting the new tables 4 and 5, given below, resp., keeping for comparison the columns " $\theta\left(^{\circ}\right)$ ", " $\mathrm{K}(k)$ ", " $\mathrm{K}_{0}(k)$ " and " $\mathrm{K}_{1}(k)$ " (in table 4), and " $\theta\left({ }^{\circ}\right)$ ", " $\mathrm{E}(k)$ ", " $\mathrm{E}_{0}(k)$ " and " $\mathrm{E}_{1}(k)$ " (in table 5), resp.

Table 4. Values of the functions $\mathrm{K}$ (part one) (this table completes and replaces table 1)

$\begin{array}{ccccc}\theta\left({ }^{\circ}\right) & \mathrm{K}(k) & \mathrm{K}_{0}(k) & \mathrm{K}_{1}(k) & \mathrm{K}_{2}(k) \\ 0 & 1.5708 & 1.5708 & 1.5708 & 1.5708 \\ 1 & 1.5709 & 1.5709 & 1.5709 & 1.5709 \\ 2 & 1.5713 & 1.5713 & 1.5713 & 1.5713 \\ 3 & 1.5719 & 1.5719 & 1.5719 & 1.5719 \\ 4 & 1.5727 & 1.5727 & 1.5727 & 1.5727 \\ 5 & 1.5738 & 1.5738 & 1.5738 & 1.5738 \\ 6 & 1.5751 & 1.5751 & 1.5751 & 1.5751 \\ 7 & 1.5767 & 1.5767 & 1.5767 & 1.5767 \\ 8 & 1.5785 & 1.5785 & 1.5785 & 1.5785 \\ 9 & 1.5805 & 1.5805 & 1.5805 & 1.5805 \\ 10 & 1.5828 & 1.5828 & 1.5828 & 1.5828 \\ 11 & 1.5854 & 1.5854 & 1.5854 & 1.5854 \\ 12 & 1.5882 & 1.5882 & 1.5882 & 1.5882 \\ 13 & 1.5913 & 1.5913 & 1.5913 & 1.5913 \\ 14 & 1.5946 & 1.5946 & 1.5946 & 1.5946 \\ 15 & 1.5981 & 1.5981 & 1.5981 & 1.5981 \\ 16 & 1.6020 & 1.6020 & 1.6020 & 1.6020 \\ 17 & 1.6061 & 1.6061 & 1.6061 & 1.6061 \\ 18 & 1.6105 & 1.6105 & 1.6105 & 1.6105 \\ 19 & 1.6151 & 1.6151 & 1.6151 & 1.6151 \\ 20 & 1.6200 & 1.6200 & 1.6200 & 1.6200 \\ 21 & 1.6252 & 1.6252 & 1.6252 & 1.6252 \\ 22 & 1.6307 & 1.6307 & 1.6307 & 1.6307 \\ 23 & 1.6365 & 1.6365 & 1.6365 & 1.6365 \\ 24 & 1.6426 & 1.6426 & 1.6426 & 1.6426 \\ 25 & 1.6490 & 1.6490 & 1.6490 & 1.6490 \\ 26 & 1.6557 & 1.6557 & 1.6557 & 1.6557 \\ 27 & 1.6627 & 1.6627 & 1.6627 & 1.6627 \\ 28 & 1.6701 & 1.6701 & 1.6701 & 1.6701 \\ 29 & 1.6777 & 1.6777 & 1.6777 & 1.6777 \\ 30 & 1.6858 & 1.6857 & 1.6858 & 1.6858 \\ 31 & 1.6941 & 1.6941 & 1.6941 & 1.6941 \\ 32 & 1.7028 & 1.7028 & 1.7028 & 1.7028 \\ 33 & 1.7119 & 1.7119 & 1.7119 & 1.7119 \\ 34 & 1.7214 & 1.7214 & 1.7214 & 1.7214 \\ 35 & 1.7312 & 1.7312 & 1.7312 & 1.7312 \\ 36 & 1.7415 & 1.7415 & 1.7415 & 1.7415 \\ 37 & 1.7522 & 1.7522 & 1.7522 & 1.7522 \\ 38 & 1.7633 & 1.7632 & 1.7633 & 1.7633 \\ 39 & 1.7748 & 1.7748 & 1.7748 & 1.7748 \\ 40 & 1.7868 & 1.7867 & 1.7868 & 1.7868\end{array}$

\begin{tabular}{ccccc}
41 & 1.7992 & 1.7992 & 1.7992 & 1.7992 \\
42 & 1.8122 & 1.8121 & 1.8122 & 1.8122 \\
43 & 1.8256 & 1.8256 & 1.8256 & 1.8256 \\
44 & 1.8396 & 1.8395 & 1.8396 & 1.8396 \\
45 & 1.8541 & 1.8540 & 1.8541 & 1.8541 \\
46 & 1.8691 & 1.8691 & 1.8691 & 1.8691 \\
47 & 1.8848 & 1.8847 & 1.8848 & 1.8848 \\
48 & 1.9011 & 1.9009 & 1.9011 & 1.9011 \\
49 & 1.9180 & 1.9178 & 1.9180 & 1.9180 \\
50 & 1.9356 & 1.9354 & 1.9356 & 1.9356 \\
51 & 1.9539 & 1.9536 & 1.9539 & 1.9539 \\
52 & 1.9729 & 1.9726 & 1.9729 & 1.9729 \\
53 & 1.9927 & 1.9923 & 1.9927 & 1.9927 \\
54 & 2.0133 & 2.0128 & 2.0133 & 2.0133 \\
55 & 2.0347 & 2.0341 & 2.0347 & 2.0347 \\
56 & 2.0571 & 2.0564 & 2.0571 & 2.0571 \\
57 & 2.0804 & 2.0795 & 2.0804 & 2.0804 \\
58 & 2.1047 & 2.1037 & 2.1047 & 2.1047 \\
59 & 2.1300 & 2.1288 & 2.1300 & 2.1300 \\
60 & 2.1565 & 2.1551 & 2.1565 & 2.1565 \\
61 & 2.1842 & 2.1825 & 2.1842 & 2.1842 \\
62 & 2.2132 & 2.2111 & 2.2132 & 2.2132 \\
63 & 2.2435 & 2.2410 & 2.2435 & 2.2435 \\
64 & 2.2754 & 2.2723 & 2.2754 & 2.2754 \\
65 & 2.3088 & 2.3051 & 2.3088 & 2.3088 \\
66 & 2.3439 & 2.3394 & 2.3439 & 2.3439 \\
67 & 2.3809 & 2.3754 & 2.3809 & 2.3809 \\
68 & 2.4198 & 2.4132 & 2.4198 & 2.4198 \\
69 & 2.4610 & 2.4530 & 2.4610 & 2.4610 \\
70 & 2.5046 & 2.4948 & 2.5045 & 2.5046 \\
70.5 & 2.5273 & 2.5165 & 2.5273 & 2.5273 \\
71 & 2.5507 & 2.5389 & 2.5507 & 2.5507 \\
71.5 & 2.5749 & & 2.5749 & 2.5749 \\
72 & 2.5998 & & 2.5998 & 2.5998 \\
72.5 & 2.6256 & & 2.6255 & 2.6256 \\
73 & 2.6521 & & 2.6521 & 2.6521 \\
73.5 & 2.6796 & & 2.6796 & 2.6796 \\
74 & 2.7081 & & 2.7081 & 2.7081 \\
74.5 & 2.7375 & & 2.7375 & 2.7375 \\
75 & 2.7681 & & 2.7680 & 2.7681 \\
75.5 & 2.7998 & & 2.7997 & 2.7998 \\
76 & 2.8327 & & 2.8326 & 2.8327 \\
76.5 & 2.8669 & & 2.8669 & 2.8669 \\
77 & 2.9026 & & 2.9025 & 2.9026 \\
77.5 & 2.9397 & & 2.9397 & 2.9397 \\
78 & 2.9786 & & 2.9785 & 2.9786 \\
78.5 & 3.0192 & & 3.0191 & 3.0192 \\
79 & 3.0617 & & 3.0616 & 3.0617 \\
79.5 & 3.1064 & & 3.1063 & 3.1064 \\
80.2 & 3.1534 & & 3.1533 & 3.1534 \\
80.6 & 3.1729 & & 3.1727 & 3.1729 \\
80.8 & 3.2132 & & 3.1927 & 3.1928 \\
81 & 3.2540 & & 3.2130 & 3.2132 \\
& & & 3.2551 & 3.2340 \\
& & & \\
\hline 5 & & & &
\end{tabular}


Table 4. Values of the functions K (part two)

\begin{tabular}{|c|c|c|c|}
\hline 81.2 & 3.2771 & 3.2769 & 3.2771 \\
\hline 81.4 & 3.2995 & 3.2992 & 3.2995 \\
\hline 81.6 & 3.3223 & 3.3221 & 3.3223 \\
\hline 81.8 & 3.3458 & 3.3455 & 3.3458 \\
\hline 82 & 3.3699 & 3.3696 & 3.3699 \\
\hline 82.2 & 3.3946 & 3.3942 & 3.3946 \\
\hline 82.4 & 3.4199 & 3.4196 & 3.4199 \\
\hline 82.6 & 3.4460 & 3.4456 & 3.4460 \\
\hline 82.8 & 3.4728 & 3.4724 & 3.4728 \\
\hline 83 & 3.5004 & 3.4999 & 3.5004 \\
\hline 83.2 & 3.5288 & 3.5283 & 3.5288 \\
\hline 83.4 & 3.5581 & 3.5575 & 3.5581 \\
\hline 83.6 & 3.5884 & 3.5877 & 3.5884 \\
\hline 83.8 & 3.6196 & 3.6188 & 3.6196 \\
\hline 84 & 3.6519 & 3.6510 & 3.6519 \\
\hline 84.2 & 3.6852 & 3.6843 & 3.6852 \\
\hline 84.4 & 3.7198 & 3.7187 & 3.7198 \\
\hline 84.6 & 3.7557 & 3.7545 & 3.7557 \\
\hline 84.8 & 3.7930 & 3.7916 & 3.7930 \\
\hline 85 & 3.8317 & 3.8302 & 3.8317 \\
\hline 85.2 & 3.8721 & 3.8704 & 3.8721 \\
\hline 85.4 & 3.9142 & 3.9122 & 3.9142 \\
\hline 85.6 & 3.9583 & 3.9560 & 3.9583 \\
\hline 85.8 & 4.0044 & 4.0018 & 4.0044 \\
\hline 86 & 4.0528 & 4.0498 & 4.0528 \\
\hline 86.2 & 4.1037 & 4.1003 & 4.1037 \\
\hline 86.4 & 4.1574 & 4.1535 & 4.1574 \\
\hline 86.6 & 4.2142 & 4.2097 & 4.2142 \\
\hline 86.8 & 4.2744 & 4.2692 & 4.2744 \\
\hline 87 & 4.3387 & 4.3325 & 4.3387 \\
\hline 87.2 & 4.4073 & 4.4001 & 4.4073 \\
\hline 87.4 & 4.4811 & 4.4726 & 4.4811 \\
\hline 87.6 & 4.5609 & 4.5507 & 4.5609 \\
\hline 87.8 & 4.6477 & 4.6354 & 4.6477 \\
\hline 88 & 4.7427 & 4.7277 & 4.7427 \\
\hline 88.2 & 4.8478 & 4.8293 & 4.8478 \\
\hline 88.4 & 4.9654 & & 4.9654 \\
\hline 88.6 & 5.0988 & & 5.0987 \\
\hline 88.8 & 5.2527 & & 5.2527 \\
\hline 89 & 5.4349 & & 5.4349 \\
\hline 89.1 & 5.5402 & & 5.5402 \\
\hline 89.2 & 5.6579 & & 5.6579 \\
\hline 89.3 & 5.7914 & & 5.7913 \\
\hline 89.4 & 5.9455 & & 5.9454 \\
\hline 89.5 & 6.1278 & & 6.1276 \\
\hline 89.6 & 6.3509 & & 6.3506 \\
\hline 89.7 & 6.6385 & & 6.6380 \\
\hline 89.8 & 7.0440 & & 7.0428 \\
\hline 89.9 & 7.7371 & & 7.7336 \\
\hline 90 & $\infty$ & $-\infty$ & $-\infty$ \\
\hline
\end{tabular}

The values string in the last column is given by:

$\mathrm{K}_{2}(k)=\frac{2}{1+\sqrt{1-k^{2}}} \mathrm{~K}_{1}\left(\frac{1-\sqrt{1-k^{2}}}{1+\sqrt{1-k^{2}}}\right)=\frac{2}{1+k^{\prime}} \mathrm{K}_{1}\left(\frac{1-k^{\prime}}{1+k^{\prime}}\right)$,

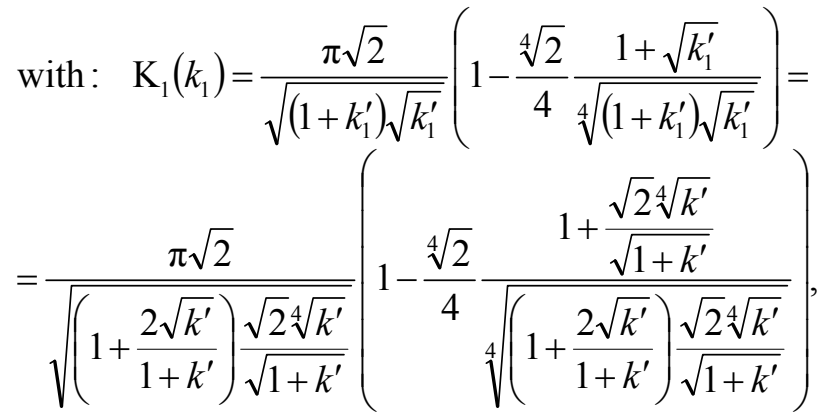

and finally the algebraic formula: $\mathrm{K}_{2}(k)=2 \mathrm{~K}_{1}\left(k_{1}\right) /(1+k)$.

Table 5. Values of the functions $\mathrm{E}$ (part one)

(this table completes and replaces table 2)

$\begin{array}{rcccc}\theta\left({ }^{\circ}\right) & \mathrm{E}(k) & \mathrm{E}_{0}(k) & \mathrm{E}_{1}(k) & \mathrm{E}_{2}(k) \\ 0 & 1.5708 & 1.5708 & 1.5708 & 1.5708 \\ 1 & 1.5707 & 1.5707 & 1.5707 & 1.5707 \\ 2 & 1.5703 & 1.5703 & 1.5703 & 1.5703 \\ 3 & 1.5697 & 1.5697 & 1.5697 & 1.5697 \\ 4 & 1.5689 & 1.5689 & 1.5689 & 1.5689 \\ 5 & 1.5678 & 1.5678 & 1.5678 & 1.5678 \\ 6 & 1.5665 & 1.5665 & 1.5665 & 1.5665 \\ 7 & 1.5649 & 1.5649 & 1.5649 & 1.5649 \\ 8 & 1.5632 & 1.5632 & 1.5632 & 1.5632 \\ 9 & 1.5611 & 1.5611 & 1.5611 & 1.5611 \\ 10 & 1.5589 & 1.5589 & 1.5589 & 1.5589 \\ 11 & 1.5564 & 1.5564 & 1.5564 & 1.5564 \\ 12 & 1.5537 & 1.5537 & 1.5537 & 1.5537 \\ 13 & 1.5507 & 1.5507 & 1.5507 & 1.5507 \\ 14 & 1.5476 & 1.5476 & 1.5476 & 1.5476 \\ 15 & 1.5442 & 1.5442 & 1.5442 & 1.5442 \\ 16 & 1.5405 & 1.5405 & 1.5405 & 1.5405 \\ 17 & 1.5367 & 1.5367 & 1.5367 & 1.5367 \\ 18 & 1.5326 & 1.5326 & 1.5326 & 1.5326 \\ 19 & 1.5283 & 1.5283 & 1.5283 & 1.5283 \\ 20 & 1.5238 & 1.5238 & 1.5238 & 1.5238 \\ 21 & 1.5191 & 1.5191 & 1.5191 & 1.5191 \\ 22 & 1.5141 & 1.5141 & 1.5141 & 1.5141 \\ 23 & 1.5090 & 1.5090 & 1.5090 & 1.5090 \\ 24 & 1.5037 & 1.5037 & 1.5037 & 1.5037 \\ 25 & 1.4981 & 1.4981 & 1.4981 & 1.4981 \\ 26 & 1.4924 & 1.4924 & 1.4924 & 1.4924 \\ 27 & 1.4864 & 1.4864 & 1.4864 & 1.4864 \\ 28 & 1.4803 & 1.4803 & 1.4803 & 1.4803 \\ 29 & 1.4740 & 1.4740 & 1.4740 & 1.4740 \\ 30 & 1.4675 & 1.4675 & 1.4675 & 1.4675 \\ 31 & 1.4608 & 1.4608 & 1.4608 & 1.4608 \\ 32 & 1.4539 & 1.4539 & 1.4539 & 1.4539 \\ 33 & 1.4469 & 1.4469 & 1.4469 & 1.4469 \\ 34 & 1.4397 & 1.4397 & 1.4397 & 1.4397 \\ 35 & 1.4323 & 1.4323 & 1.4323 & 1.4323 \\ 36 & 1.4248 & 1.4248 & 1.4248 & 1.4248 \\ 37 & 1.4171 & 1.4171 & 1.4171 & 1.4171 \\ 38 & 1.4092 & 1.4093 & 1.4092 & 1.4092 \\ 39 & 1.4013 & 1.4013 & 1.4013 & 1.4013 \\ 40 & 1.3931 & 1.3932 & 1.3931 & 1.3931\end{array}$


Table 5. Values of the functions E (part two)

$\begin{array}{ccccc}41 & 1.3849 & 1.3849 & 1.3849 & 1.3849 \\ 42 & 1.3765 & 1.3765 & 1.3765 & 1.3765 \\ 43 & 1.3680 & 1.3680 & 1.3680 & 1.3680 \\ 44 & 1.3594 & 1.3594 & 1.3594 & 1.3594 \\ 45 & 1.3506 & 1.3507 & 1.3506 & 1.3506 \\ 46 & 1.3418 & 1.3419 & 1.3418 & 1.3418 \\ 47 & 1.3329 & 1.3330 & 1.3329 & 1.3329 \\ 48 & 1.3238 & 1.3239 & 1.3238 & 1.3238 \\ 49 & 1.3147 & 1.3148 & 1.3147 & 1.3147 \\ 50 & 1.3055 & 1.3057 & 1.3055 & 1.3055 \\ 51 & 1.2963 & 1.2964 & 1.2963 & 1.2963 \\ 52 & 1.2870 & 1.2872 & 1.2870 & 1.2870 \\ 53 & 1.2776 & 1.2778 & 1.2776 & 1.2776 \\ 54 & 1.2681 & 1.2684 & 1.2681 & 1.2681 \\ 55 & 1.2587 & 1.2590 & 1.2587 & 1.2587 \\ 56 & 1.2492 & 1.2496 & 1.2492 & 1.2492 \\ 57 & 1.2397 & 1.2401 & 1.2397 & 1.2397 \\ 58 & 1.2301 & 1.2307 & 1.2301 & 1.2301 \\ 59 & 1.2206 & 1.2212 & 1.2206 & 1.2206 \\ 60 & 1.2111 & 1.2118 & 1.2111 & 1.2111 \\ 61 & 1.2015 & 1.2024 & 1.2015 & 1.2015 \\ 62 & 1.1920 & 1.1930 & 1.1920 & 1.1920 \\ 63 & 1.1826 & 1.1838 & 1.1826 & 1.1826 \\ 64 & 1.1732 & 1.1745 & 1.1732 & 1.1732 \\ 65 & 1.1638 & 1.1654 & 1.1638 & 1.1638 \\ 66 & 1.1545 & 1.1564 & 1.1545 & 1.1545 \\ 67 & 1.1453 & 1.1475 & 1.1453 & 1.1453 \\ 68 & 1.1362 & 1.1387 & 1.1362 & 1.1362 \\ 69 & 1.1272 & 1.1301 & 1.1273 & 1.1272 \\ 70 & 1.1184 & 1.1217 & 1.1184 & 1.1184 \\ 70.5 & 1.1140 & 1.1176 & 1.1140 & 1.1140 \\ 71 & 1.1096 & 1.1135 & 1.1096 & 1.1096 \\ 71.5 & 1.1053 & & 1.1053 & 1.1053 \\ 72 & 1.1011 & & 1.1011 & 1.1011 \\ 72.5 & 1.0968 & & 1.0968 & 1.0968 \\ 73 & 1.0927 & & 1.0927 & 1.0927 \\ 73.5 & 1.0885 & & 1.0885 & 1.0885 \\ 74 & 1.0844 & & 1.0844 & 1.0844 \\ 74.5 & 1.0804 & & 1.0804 & 1.0804 \\ 75 & 1.0764 & & 1.0764 & 1.0764 \\ 75.5 & 1.0725 & & 1.0725 & 1.0725 \\ 76 & 1.0686 & & 1.0686 & 1.0686 \\ 76.5 & 1.0648 & & 1.0648 & 1.0648 \\ 77 & 1.0611 & & 1.0611 & 1.0611 \\ 77.5 & 1.0574 & & 1.0574 & 1.0574 \\ 78 & 1.0538 & & 1.0538 & 1.0538 \\ 78.5 & 1.0502 & & 1.0503 & 1.0502 \\ 79 & 1.0468 & & 1.0468 & 1.0468 \\ 79.5 & 1.0434 & & 1.0435 & 1.0434 \\ 80.4 & 1.0401 & & 1.0402 & 1.0401 \\ 80.6 & 1.0388 & & 1.0389 & 1.0388 \\ 80.8 & 1.0363 & & 1.0376 & 1.0375 \\ & & & 1.0364 & 1.0363 \\ & & & \\ & & & \end{array}$

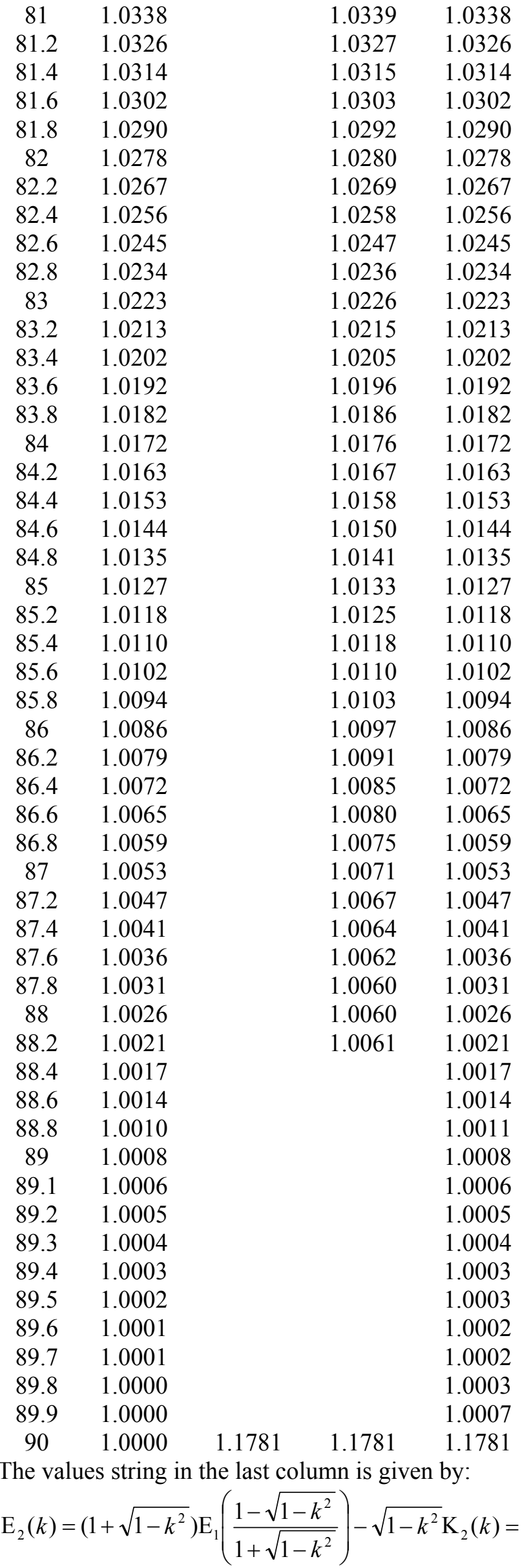


$=\left(1+k^{\prime}\right) \mathrm{E}_{1}\left(\frac{1-k^{\prime}}{1+k^{\prime}}\right)-k^{\prime} \mathrm{K}_{2}(k)=$

$=\left(1+k^{\prime}\right) \mathrm{E}_{1}\left(\frac{1-k^{\prime}}{1+k^{\prime}}\right)-\frac{2 k^{\prime}}{1+k^{\prime}} \mathrm{K}_{1}\left(\frac{1-k^{\prime}}{1+k^{\prime}}\right)$, with :

$\frac{1-k^{\prime}}{1+k^{\prime}}=k_{1}$ (descendingLanden transformation), getting

$\mathrm{E}_{1}\left(k_{1}\right)=\frac{\pi}{4}\left[\frac{3}{2}\left(1+\sqrt{k_{1}^{\prime}}\right)^{2}-\sqrt{2} \sqrt{1+k_{1}^{\prime}} \sqrt[4]{k_{1}^{\prime}}\right]-k_{1}^{\prime} \cdot \mathrm{K}_{1}\left(k_{1}\right)$,

and: $\quad \mathrm{K}_{1}\left(k_{1}\right)=\frac{\pi \sqrt{2}}{\sqrt{\left(1+k_{1}^{\prime}\right) \sqrt{k_{1}^{\prime}}}}\left(1-\frac{\sqrt[4]{2}}{4} \frac{1+\sqrt{k_{1}^{\prime}}}{\sqrt[4]{\left(1+k_{1}^{\prime}\right) \sqrt{k_{1}^{\prime}}}}\right)$,

previously given, thus getting:

$$
\begin{aligned}
\mathrm{E}_{1}\left(k_{1}\right)= & \frac{\pi}{4}\left[\frac{3}{2}\left(1+\sqrt{k_{1}^{\prime}}\right)^{2}-\sqrt{2} \sqrt{\left(1+k_{1}^{\prime}\right) \sqrt{k_{1}^{\prime}}}\right]- \\
& -\frac{\pi k_{1}^{\prime} \sqrt{2}}{\sqrt{\left(1+k_{1}^{\prime}\right) \sqrt{k_{1}^{\prime}}}}\left(1-\frac{\sqrt[4]{2}}{4} \frac{1+\sqrt{k_{1}^{\prime}}}{\sqrt[4]{\left(1+k_{1}^{\prime}\right) \sqrt{k_{1}^{\prime}}}}\right)= \\
= & \frac{\pi}{4}\left[\frac{3}{2}\left(1+\sqrt{k_{1}^{\prime}}\right)^{2}-\sqrt{2\left(1+k_{1}^{\prime}\right) \sqrt{k_{1}^{\prime}}}-\right. \\
& \left.-\frac{k_{1}^{\prime} \sqrt{2}}{\sqrt{\left(1+k_{1}^{\prime}\right) \sqrt{k_{1}^{\prime}}}}\left(4-\frac{\sqrt[4]{2}\left(1+\sqrt{k_{1}^{\prime}}\right)}{\sqrt[4]{\left(1+k_{1}^{\prime}\right) \sqrt{k_{1}^{\prime}}}}\right)\right] .
\end{aligned}
$$

Expressing $k_{1}^{\prime}\left(k^{\prime}\right): \quad k_{1}^{\prime}=\left(1-k_{1}^{2}\right)^{1 / 2}=2\left(k^{\prime}\right)^{1 / 2} /\left(1+k^{\prime}\right)$, (ascending Landen transformation), and replacing it:

$$
\begin{aligned}
& \mathrm{E}_{1}\left(k_{1}\right)=\frac{\pi}{4}\left[\frac{3}{2}\left(1+\frac{\sqrt{2} \sqrt[4]{k^{\prime}}}{\sqrt{1+k^{\prime}}}\right)^{2}-\sqrt{2\left(1+\frac{2 \sqrt{k^{\prime}}}{1+k^{\prime}}\right) \frac{\sqrt{2} \sqrt[4]{k^{\prime}}}{\sqrt{1+k^{\prime}}}}\right. \\
& -\frac{\sqrt{2} \cdot \frac{2 \sqrt{k^{\prime}}}{1+k^{\prime}}}{\sqrt{\left(1+\frac{2 \sqrt{k^{\prime}}}{1+k^{\prime}}\right) \frac{\sqrt{2} \sqrt[4]{k^{\prime}}}{\sqrt{1+k^{\prime}}}}}\left[4-\frac{\left.\sqrt[4]{k^{\prime}}\right)}{\left.\sqrt[4]{1+k^{\prime}}\right)}\right] \\
& \left.\sqrt[4]{\left(1+\frac{2 \sqrt{k^{\prime}}}{1+k^{\prime}}\right) \frac{\sqrt{2} \sqrt[4]{k^{\prime}}}{\sqrt{1+k^{\prime}}}}\right)
\end{aligned}
$$

and finally: $\mathrm{E}_{2}(k)=\left(1+k^{\prime}\right) \mathrm{E}_{1}\left(k_{1}\right)-k^{\prime} \mathrm{K}_{2}(k)$, where $\mathrm{K}_{2}(k)$ was given just before table 5 , so getting another purely algebraic formula (the most accurate, just seemingly intricate), the $3^{\text {rd }}$ set of closed analytic formulas being given by the recurrences: $\mathrm{K}_{2}(k)=2 \mathrm{~K}_{1}\left(k_{1}\right) /\left(1+k^{\prime}\right) ; \mathrm{E}_{2}(k)=\left(1+k^{\prime}\right) \mathrm{E}_{1}\left(k_{1}\right)-k^{\prime} \mathrm{K}_{2}(k)$. Noting: $k_{1}^{\prime}=x$ and $\left[(1+x) \cdot x^{1 / 2}\right]^{1 / 2}=y$, one can write:

$$
\begin{aligned}
& \mathrm{K}_{2}(k)=\pi\left(2 / k^{\prime}\right)^{1 / 2} \cdot(x / y)\left[1-\left(2^{1 / 4} / 4\right)\left(1+x^{1 / 2}\right) / y^{1 / 2}\right] ; \\
& \mathrm{E}_{2}(k)=\pi\left(k^{\prime}\right)^{1 / 2} /(2 x) \cdot\left\{(3 / 2)\left(1+x^{1 / 2}\right)^{2}-2^{1 / 2} y-\right. \\
& \left.\quad-2^{1 / 2}(x / y)\left[4-2^{1 / 4}\left(1+x^{1 / 2}\right) / y^{1 / 2}\right]\right\}-k^{\prime} \mathrm{K}_{2}(k), \text { resp., }
\end{aligned}
$$

much simpler than previous ones (for calculation only). The validity of all approximate sets is limited to $k \in\left[0, k_{\text {extr }}\right) ; k_{\text {ext }}$ $\leq 1$, “extr" $\equiv$ extremum (max. for $\mathrm{K}$, and min. for $\mathrm{E} ; k_{\max } \neq k_{\min }$ ) (see figs. $1 \& 2$ - the dashed black lines, and the solid red ones, resp.). The higher the " $n$ " index (of the $\left(\mathrm{K}_{\mathrm{n}-1}, \mathrm{E}_{\mathrm{n}-1}\right)$ approximation set) value is, the better this approximation is and the closer to the right domain's end $(k=1)$ the extremum is located. We will cancel the recurrent-iterative scheme (stopping it to a specific " $n$ " index value) when the maximum relative error (over the whole valid domain of variation $k \in[0$, $\left.k_{\text {extr }}\right)$ ) becomes lesser than the desired (required) accuracy. The first important application of the results obtained in chapter 4 consists in determining the locations of the extrema values $k_{\text {extr }}\left(k_{\max }\right.$ for $\mathrm{K}_{\mathrm{n}-1}(k)$ and $k_{\min }$ for $\left.\mathrm{E}_{\mathrm{n}-1}(k)\right)$, corresponding to the annulment of their first derivatives with respect to $k$, using the relations: $\mathrm{K}_{\mathrm{n}-1}^{\prime}(k)=d \mathrm{~K}_{\mathrm{n}-1}(k) / d k=0 ; \mathrm{E}_{\mathrm{n}-1}^{\prime}(k)=d \mathrm{E}_{\mathrm{n}-1}(k) / d k=0$, and adding the recurrent definitions for $\mathrm{K}_{\mathrm{n}-1}(k)$ and $\mathrm{E}_{\mathrm{n}-1}(k)$. The $1^{\text {st }}$ ODE above gives the value $k_{\max }$ and the $2^{\text {nd }}$ one gives the value $k_{\min }$. Each of these ODEs has really two solutions. Besides the searched for one, both ODEs admit the solution $k=0$, corresponding to a minimum for $\mathrm{K}_{\mathrm{n}-1}(k)$ and to a maximum for $\mathrm{E}_{\mathrm{n}-1}(k)$, both with the value $\pi / 2$ (for both approximate and exact functions: $\mathrm{K}_{\mathrm{n}-1}(0)=\mathrm{E}_{\mathrm{n}-1}(0)=\mathrm{K}(0)=\mathrm{E}(0)=\pi / 2$, with: $\left.\mathrm{K}_{\mathrm{n}-1}^{\prime}(0)=\mathrm{E}_{\mathrm{n}-1}^{\prime}(0)=\mathrm{K}^{\prime}(0)=\mathrm{E}^{\prime}(0)=0\right)$, but with : $\mathrm{K}_{\mathrm{n}-1}^{\prime \prime}(0)>0$ and $\mathrm{K}^{\prime \prime}(0)>0-\mathrm{a}$ minimum, while : $\mathrm{E}_{\mathrm{n}-1}^{\prime \prime-1}(0)<0$ and $\mathrm{E}^{\prime \prime}(0)<0-$ a maximum).

Thus one knows now the values $k_{\max }$ and $k_{\min }$ (the right ends of the validity domains of the approximate functions). In order to evaluate the accuracy of the $3^{\text {rd }}$ set $\left(K_{2}, E_{2}\right)$, similarly as for the previous two sets, $\left(\mathrm{K}_{0}, \mathrm{E}_{0}\right)$ and $\left(\mathrm{K}_{1}, \mathrm{E}_{1}\right)$, we will define the following relative error functions: $\varepsilon_{\mathrm{K}_{2}}(k)=\mathrm{K}_{2}(k) / \mathrm{K}(k)-1$, and: $\varepsilon_{\mathrm{E}_{2}}(k)=\mathrm{E}_{2}(k) / \mathrm{E}(k)-1$, for the approximate formulas of $1^{\text {st }} \& 2^{\text {nd }}$ kind integrals. Their values are given in table 6 , expressed in thousandths (\%o). These errors were calculated for the $3^{\text {rd }} \operatorname{set}\left(\mathrm{K}_{2}, \mathrm{E}_{2}\right)$ only, with an increment of $0^{\circ} .2$ in the field $\theta \in\left[84^{\circ}, 89^{\circ}\right]$ of the domain, and of $0^{\circ} .1$ beyond $89^{\circ}$. To get table 6 , in table 3 were suppressed the columns $\varepsilon_{\mathrm{K}_{0}}(\% 0), \varepsilon_{\mathrm{E}_{0}}(\% \mathrm{o})$ (the most inaccurate) and were inserted the columns $\varepsilon_{\mathrm{K}_{2}}(\%)$, $\varepsilon_{\mathrm{E}_{2}}(\%)$, keeping for comparison the columns " $\theta\left(^{\circ}\right)$ ", " $k=\sin \theta$ ", " $\varepsilon_{\mathrm{K}_{1}}(\% \mathrm{o})$ " and " $\varepsilon_{\mathrm{E}_{1}}(\% \mathrm{o})$ " (from table 3$)$, only.

Table 6. Relative errors $\varepsilon$ distribution (this table completes and replaces table 3 )

$\begin{array}{cccccc}\theta\left(^{\circ}\right) & k=\sin \theta & \varepsilon_{\mathrm{K}_{1}}(\% \mathrm{o}) & \varepsilon_{\mathrm{K}_{2}}(\% \mathrm{o}) & \varepsilon_{\mathrm{E}_{1}}(\% \mathrm{o}) & \varepsilon_{\mathrm{E}_{2}}(\% \mathrm{o}) \\ 84.8 & 0.99588 & -0.369 & 0 & +0.607 & 0 \\ 85 & 0.99619 & -0.396 & 0 & +0.592 & 0 \\ 85.2 & 0.99649 & -0.451 & 0 & +0.705 & 0 \\ 85.4 & 0.99678 & -0.500 & 0 & +0.748 & 0 \\ 85.6 & 0.99705 & -0.582 & 0 & +0.823 & 0 \\ 85.8 & 0.99731 & -0.652 & 0 & +0.932 & 0 \\ 86 & 0.99756 & -0.737 & 0 & +1.076 & 0 \\ 86.2 & 0.99780 & -0.832 & 0 & +1.160 & 0 \\ 86.4 & 0.99803 & -0.945 & 0 & +1.284 & 0 \\ 86.6 & 0.99824 & -1.077 & 0 & +1.453 & 0 \\ 86.8 & 0.99844 & -1.214 & 0 & +1.571 & 0 \\ 87 & 0.99863 & -1.421 & 0 & +1.743 & 0 \\ 87.2 & 0.99881 & -1.626 & 0 & +1.976 & 0 \\ 87.4 & 0.99897 & -1.894 & 0 & +2.275 & 0 \\ 87.6 & 0.99912 & -2.234 & 0 & +2.553 & 0 \\ 87.8 & 0.99926 & -2.655 & 0 & +2.922 & 0 \\ 88 & 0.99939 & -3.156 & 0 & +3.397 & 0 \\ 88.2 & 0.99951 & -3.808 & 0 & +4.004 & 0\end{array}$




$\begin{array}{cccccc}88.4 & 0.99961 & - & 0 & - & 0 \\ 88.6 & 0.99970 & - & 0 & - & 0 \\ 88.8 & 0.99978 & - & 0 & - & 0 \\ 89 & 0.99985 & - & 0 & - & 0 \\ 89.1 & 0.99988 & - & 0 & - & 0 \\ 89.2 & 0.99990 & - & 0 & - & 0 \\ 89.3 & 0.99993 & - & 0 & - & 0 \\ 89.4 & 0.99995 & - & 0 & - & 0 \\ 89.5 & 0.99996 & - & & - & \\ 89.6 & 0.99998 & - & & - & \\ 89.7 & 0.99999 & - & & - & \\ 89.8 & 0.99999 & - & & - & \\ 89.9 & 1.00000 & - & & - & \\ 90 & 1.00000 & -2000 & -2000 & 178.097 & 178.097\end{array}$

The relative errors strings are stopped for values $\geq 4 \%$. From the tables 3 and 6 one can see that, for any $n^{\text {th }}$ set of approximation and at any value $k=\sin \theta$ of the elliptic integrals' modulus, $\varepsilon_{\mathrm{K}}<0\left(\mathrm{~K}_{\mathrm{n}}<\mathrm{K}\right)$ and $\varepsilon_{\mathrm{E}}>0\left(\mathrm{E}_{\mathrm{n}}>\mathrm{E}\right)$, i.e. $\mathrm{K}$ is approximated by lack, while $\mathrm{E}$ is approximated by excess. Similarly to the $3^{\text {rd }}$ set $\left[\mathrm{K}_{2}(k), \mathrm{E}_{2}(k)\right]$, expressed in algebraic functions, one can build the $3^{\text {rd }}$ set $\left[\mathrm{K}_{2}(\theta), \mathrm{E}_{2}(\theta)\right]$, expressed in trigonometric functions, replacing $k^{\prime}$ in $\left[\mathrm{K}_{2}(k), \mathrm{E}_{2}(k)\right]$ set by $\cos \theta$ and applying usual trigonometric identities. The comparative series representations and the graphic comparison are superfluous, due to the great accuracy of the approximate values given by the $3^{\text {rd }}$ set (practically identical to the exact ones, which could be already noticed from the analysis of the $2^{\text {nd }}$ set, this showing the fast converging character of this recurrent-iterative scheme). Except for the right domain's end $(k=1)$, the $3^{\text {rd }}$ set of approximation $\left(\mathrm{K}_{2}, \mathrm{E}_{2}\right)$, even more accurate than the $2^{\text {nd }}$ one $\left(\mathrm{K}_{1}, \mathrm{E}_{1}\right)$, may be considered and successfully used instead of the exact values of $\mathrm{K}(k)$ and $\mathrm{E}(k)$ from mathematical tables (the $3^{\text {rd }}$ set $\left(\mathrm{K}_{2}, \mathrm{E}_{2}\right)$ can be already used until $\theta=89^{\circ} .7$ $(k=0.99999)-\mathrm{a}$ false minimum, for the $\mathrm{E}_{2}(k)$ function; for the $2^{\text {nd }}$ set this takes place at $\theta=88^{\circ}(k=0.99939)$; the graphs of all $\mathrm{E}_{\mathrm{n}}(k)$ pass through the point $(1,3 \pi / 8)$; for $k$ tending to unity, the graphs of all $\mathrm{K}_{\mathrm{n}}(k)$ go toward $(-\infty)$; the higher $n^{\text {th }}$ sets $(n \geq 4)$ give a much better accuracy). Unlike these tables (and in addition to them), all these approximation sets (the $1^{\text {st }}, 2^{\text {nd }}, 3^{\text {rd }}$ and the higher $\mathrm{n}^{\text {th }}(\mathrm{n} \geq 4)$ ones) allow performing the analytic study of variation of the functions in which $\mathrm{K}(k)$ and / or $\mathrm{E}(k)$ appear /s, using the derivatives of the $1^{\text {st }}$ and $2^{\text {nd }}$ order (with respect to $k$ ).

Remarks: 1. As a first step in applying the new recurrentiterative scheme, just the obtaining of the $2^{\text {nd }}$ set $\left(\mathrm{K}_{1}, \mathrm{E}_{1}\right)$ as a function of the $1^{\text {st }}$ one $\left(\mathrm{K}_{0}, \mathrm{E}_{0}\right)$ (in chapter 2$)$ may be considered, i.e. this scheme starts really at the $2^{\text {nd }}$ set. It is to be highlighted that the used method is a purely analytic one (neither numerical procedures nor sophisticated computer programs). Its simplicity, accuracy and fast convergence, as well as its limitations depend exclusively on the correct choice of its starting point (approximation set) $\left(\mathrm{K}_{0}, \mathrm{E}_{0}\right)$; it must be quite precise, and especially, as simple as possible.
The starting approximate formula-definition giving $\mathrm{E}_{0}(k)$ was suggested to the author by an old approximate formula (Peano, [18], [19]) for the perimeter $L$ of an ellipse of semiaxes $a$ and $b(\leq a)$ : $L \approx \pi\left[1.5(a+b)-(a b)^{1 / 2}\right]-$ a good (\& simple) approximation with the best accuracy for $b=a$ (circle): $L=2 \pi a$, and the worst one for $b=0$ (plane plate): $L=1.5 \pi a$, instead of $L=4 a$ (or optimized Peano's law: $L_{1} \approx \pi\left[1.32(a+b)-0.64(a b)^{1 / 2}\right.$, with the smallest overall error [20](about 7 times smaller than that of the original law); for $b=a: L_{1}=L=2 \pi a$, and for $b=0: L_{1}=1.32 \pi a$, much closer to the exact value $L=4 a$ ). For its behaviour at low $b / a$ ratios, this formula is not found on the list of the very accurate (but not simple) approximations [20] (Padé, Jacobsen, Ramanujan (2 expressions), Rackauckas), all expressed in terms of the particular ratio $h=[(a-b) /(a+b)]^{2}$. Thus a reliable approximate (by excess) formula-definition was obtained (see chapter 2) for the Legendre complete elliptic integral of the $2^{\text {nd }}$ kind (in the $1^{\text {st }}$ set of approximation): $\mathrm{E}_{0}(k)=(\pi / 4)\left[1.5\left(1+k^{\prime}\right)-\left(k^{\prime}\right)^{0,5}\right]$, with $k^{\prime}=\left(1-k^{2}\right)^{0,5}$. It can be seen that the error committed if in the expansion in series of powers (of $k$ ) we stopped at the term of rank 5 (see chapter 4$)$, is $(3 / 16384) k^{8}$ only, i.e. small enough. As for the pair approximate formula-definition giving $\mathrm{K}_{0}(k)$, this was obtained using the previous one for $\mathrm{E}_{0}(k)$ and applying the definition of the first derivative of $\mathrm{E}(k)$ with respect to $k$. $d \mathrm{E}(k) / d k=[\mathrm{E}(k)-\mathrm{K}(k)] / k$ (see chapter 4), thus getting: $\mathrm{K}(k)=\mathrm{E}(k)-k[\mathrm{dE}(k) / \mathrm{d} k]$, and replacing $\mathrm{K}(k)$ and $\mathrm{E}(k)$ by their $1^{\text {st }}$ approximations: $\mathrm{K}_{0}(k)$ and the previously given $\mathrm{E}_{0}(k)$, getting: $\mathrm{K}_{0}(k)=\pi\left[1 /\left(k^{0}\right)^{0,5}-\left(1 / 2^{1,5}\right)\left(1+k^{\prime}\right)^{0,5} /\left(k^{k}\right)^{0,75}\right]($ see ch. 2$)$. Being practically generated by the same mathematical source, $\mathrm{K}_{0}(k)$ and $\mathrm{E}_{0}(k)$ vary (ordinates, slopes, asymptote, extrema, concavities, convexities, inflections) in perfectly correlated way. So, at the value $k_{\text {ext }}$ corresponding to a false minimum for $\mathrm{E}_{0}(k)$, $\mathrm{K}_{0}(k)$ must equate $\mathrm{E}_{0}(k)$, to satisfy the annulment of $d \mathrm{E}_{0}(k) / d k$. In order to prepare this action, $\mathrm{K}_{0}(k)$ must stop its vertiginous ascension to $\infty$, making a false inflection, followed by a false maximum at $k_{\mathrm{Extr}}<k_{\mathrm{extr}}$ and a vertiginous (with $k=1-$ vertical asymptote) fall toward $(-\infty)$; so $\mathrm{K}_{0}=\mathrm{E}_{0}$ at $k=0$ and $k=k_{\text {extr }}$. To minimise all these unwished events, limiting them to a very thin region in the neighbourhood of the right domain's end, it was necessary to apply the descending Landen transformation, passing from $k$ to $k_{1}=\left(1-k^{y}\right)(1+k) \leq k$, where all goes well, maintaining all advantages of the asymptotic behaviour of the new approximate correlated functions $\left(\mathrm{K}_{\mathrm{n}}, \mathrm{E}_{\mathrm{n}}\right)$, i.e. applying a higher $\mathrm{n}^{\text {th }}(\mathrm{n} \geq 2)$ set of approximation (repeating this scheme until the desired (required) accuracy for $\left(\mathrm{K}_{\mathrm{n}}, \mathrm{E}_{\mathrm{n}}\right)$ is obtained; fortunately, this scheme is fast converging); though it keeps the limitation at $k=1$, Peano's optimized law accelerates the scheme. 2. Besides the two formulas for transforming the modulus $k$ (using the descending Landen transformation), there are other two formulas (using the ascending Landen transformation), which are not of interest in the recurrent-iterative scheme: $\mathrm{K}(k)=\frac{1}{1+k} \mathrm{~K}\left(\frac{2 \sqrt{k}}{1+k}\right) ; \mathrm{E}(k)=\frac{1+k}{2} \mathrm{E}\left(\frac{2 \sqrt{k}}{1+k}\right)+\frac{k^{\prime 2}}{2} \mathrm{~K}(k)$, passing from $k$ to $k_{2}=2 k^{1 / 2} /(1+k) \geq k ; k_{2}=k$ for $k=0 ; 1$. 
Appendix' references:

[16] Landen, J.: XXXVI. A Disquisition Concerning Certain Fluents, which are Assignable by the Arcs of the Conic Sections; Wherein are Investigated Some New and Useful Theorems for Computing Such Fluents, Philosophical Transactions of the Royal Society of London, vol. 61 (1771), pp. 298 - 309;

https://doi.org/doi:10.1098/rstl.1771.0037

[17] Landen, J.: XXVI. An Investigation of a General Theorem for Finding the Length of Any Arc of Any Conic Hyperbola, by means of Two Elliptic Arcs, with Some Other New and Useful Theorems Deduced Therefrom, Philosophical Transactions of the Royal Society of London, vol. 65 (1775), pp. 283 - 289;

https://doi.org/doi:10.1098/rstl.1775.0028

[18] Peano, G.: Applicazioni geometriche del calcolo infinitesimale, Fratelli Bocca Editori, Torino, 1887; (in Italian), p. 233; the approximate formula for the ellipse perimeter was: $L \approx \pi(a+b)+(\pi / 2)\left(a^{1 / 2}-b^{1 / 2}\right)^{2}$.
[19] Peano, G.: VIII An approximation formula for the perimeter of the ellipse, 1889, pp. $135-136$ in Selected Works of Giuseppe Peano, Translated and edited, with a biographical sketch and bibliography, by Hubert C. Kennedy; Series: Heritage; Copyright Date: 1973; Published by: University of Toronto Press; Pages: 262; the approximate formula for ellipse perimeter (due to J. Boussinesq in the Comptes rendus, Académie des Sciences, Paris, 1889 , p. 695) was given in the well-known equivalent form: $L \approx \pi\left[3(a+b) / 2-(a b)^{1 / 2}\right]$; https://www.jstor.org/stable/10.3138/j.ctt1vxmd8x [20] Sýkora, St.: Approximations of Ellipse Perimeters and of the Complete Elliptic Integral $\mathrm{E}(\mathrm{x})$. Review of known formulae, Review by Stanislav Sýkora, Extra Byte, Via R.Sanzio 22C, Castano Primo, Italy 20022, in Stan's Library, Ed. S. Sýkora, Vol.I; First release: Dec. 27, 2005. Permalink via DOI: 10.3247/SL1Math05.004; http://www.ebyte.it/library/docs/math05a/EllipsePer imeterApprox $05 . \mathrm{html}$

\section{Creative Commons Attribution License 4.0 (Attribution 4.0 International, CC BY 4.0)}

This article is published under the terms of the Creative Commons Attribution License 4.0

https://creativecommons.org/licenses/by/4.0/deed.en_US 